\title{
Deformances: recorridos para una cartografía teatral de las desobediencias sexo- genéricas en el Centro Cultural Rojas (1984-2014)
}

Guillermina Bevacqua

CONICET - IHAAyL, Facultad de Filosofía y Letras, Universidad de Buenos Aires, Argentina mina_bevacqua@hotmail.com

Fecha de recepción: 24/03/2019. Fecha de aceptación: 03/05/2019.

\begin{abstract}
Resumen
En la década del ochenta, en el Centro Cultural Rojas de la Universidad de Buenos Aires, Batato Barea, en su devenir claun-travesti-literario, propuso una dramaturgia corporal que desacataba las lógicas del cistema [sic] sexo-género. En el nuevo milenio, en el marco de las actividades desarrolladas por el Área de Tecnologías de Género de la mencionada institución, su figura fue evocada, de manera espectral, a través de una programación escénica que dialogó con el movimiento social de las travestis de la ciudad de Buenos Aires. A partir de dicha intersección, en el Rojas se puede trazar una cartografía teatral de las desobediencias sexo-genéricas en el periodo 1984-2014. Para dar cuenta del perfil institucional que posibilitó este recorrido, en la primera parte de este trabajo, se ofrece un panorama historiográfico del Centro Cultural Rojas. Luego, en la segunda parte, se propone reflexionar en torno a la caracterización de esta cartografía. Por último, se explicita el concepto deformance, en tanto categoría contra-productiva bajo la cual inscribir un corpus de artistas que participó en la institución, de manera intermitente, a lo largo de sus 30 años.
\end{abstract}

\section{Deformances: Possibilities for a Theatrical Cartography of Gender Disobediences at the Centro Cultural Rojas (1984-2014)}

\begin{abstract}
In the eighties, at the Centro Cultural Ricardo Rojas (C.C.R.R) of the University of Buenos Aires, Batato Barea (self-defined as a literary-transvestite-clown) proposed a body dramaturgy that disregarded the logic of the gender cystem [sic]. In the new millennium, within the framework of the activities developed by the Gender Technologies Area of the aforementioned institution, his figure was evoked, in a spectral manner, through a performing arts program that dialogued with the social movement of the transvestites of Buenos Aires. Based on that intersection, a theatrical cartography of gender disobediences can be traced at the C.C.R.R in the period 1984-2014. To
\end{abstract}

Palabras clave

Centro Cultural Rojas Cartografía teatral

Desobediencias sexo-genéricas deformances

Keywords

Centro Cultural Rojas Theatrical Cartography Gender Disobediences Deformances 
understand the institutional profile that made this possible, the first part of this study offers a historiographical panorama of the Centro Cultural Ricardo Rojas. Then, the second part proposes a reflection on the characterization of this cartography. Finally, the concept of deformance is presented and analyzed as a counter-productive category under which we can register a corpus of artists that participated in the institution, intermittently, throughout its 30 years of existence.

\section{Pliegues de un corpus sexo-genérico desobediente en el Centro Cultural Rojas}

En la década del ochenta, Batato Barea propuso una experiencia de lo corporal que, desarticulando mandatos pre-establecidos, convocó la exploración de formas de subjetivación alternativas que escapaban de las lógicas de clasificación binarias del sistema sexo-género. En diálogo con la prensa, él sostenía: "No es que no me sienta travesti. No hago nada para parecerlo. Si la gente me llama así es porque hay ciertos rótulos sociales. Pero lo cierto es que no me interesa para nada parecerme a una mujer" (en s/d, 1991). En el desinterés de responder a modelizaciones y categorías sociales -ficciones somatopolíticas, en términos de Paul B. Preciado (2009)-, el performer se deslindaba del imaginario social de la travesti. En principio, fue un juego escénico performático cuando se llamó claun travesti. Al hacerlo, se inscribió en una genealogía minoritaria en el campo de las artes escénicas, la del clown, el payaso o el bufón de la corte. En el centro del poder de la representación, el performer devino travesti. Sin embargo, como indicó en la prensa, lejos de un mero acto de imitación de un sistema de significación por otro, su performatividad apeló a dislocar los marcos de legibilidad de lo que (hegemónicamente) se considera hombre- mujer, inclusive, travesti.

En la actualidad, la declaración de Batato Barea despierta una zona de indagaciones críticas para proyectar, de manera espectral, el vínculo de su figura con el activismo sexo-genérico desobediente del nuevo milenio. En este portal de radicalidad, el locus estético de Barea resuena en las micropolíticas de un cuerpo que exhorta al llamado des-identitario: "iINVENTÉMOSNOS LEJOS DEL HOMBRE QUE NOS IMPONEN Y LA MUJER QUE DELIRAN QUE DEBEMOS SER!" ([la mayúscula es del texto]), tal como convocó Marlene Wayar ${ }^{1}$ (2007: 2) en el primer editorial de El Teje. Primer periódico travesti latinoamericano, una publicación impresa del Centro Cultural Rojas realizada por el Área de Comunicación y el Área de Tecnologías de Género (coordinadas por María Moreno y Paula Viturro, respectivamente), junto con la Asociación Futuro Trans-Genérico y con el respaldo económico del Centro Cultural de España en Buenos Aires. Entre 2007 y 2012, se publicaron siete números, disponibles en www. rojas.uba.ar/contenidos/revistas/index revistas.php. Marlene Wayar, integrante de dicha Área y directora de la publicación, da cuenta de las resonancias de Barea en el proyecto cultural y artístico que impulsó, Al señalar que esta re-apropiación:

Significa un intento de la comunidad travesti por recuperar su historia, su cultura y todo aquello que como comunidad hemos creado y trabajado y que nunca se nos ha reconocido. Los pocos casos en que fue reconocido Perlongher, Lemebel, Batato Barea nos han sido expropiados porque somos justamente las travestis, las que no podemos acceder a su poesía, a su cultura, a su lectura. Siempre hemos estado excluidas hasta de nuestros propios artistas. Significa de una vez por toda arrebatar lo que nos pertenece, arrebatarles la dignidad que nos han robado y empezar a prohibirles que se paren un peldaño arriba nuestro (Wayar en Lucero, 2007 [en línea]).

De acuerdo con estas reflexiones, se establece un vínculo entre el proyector creador de Barea y su actualización en la propuesta editorial y el programa curatorial de
1. Se puede advertir que la exhortación des-identitaria de Marlene Wayar se inscribe en un movimiento más extenso en el cual, parafraseando a Paul B. Preciado, las bolleras no son mujeres, los maricas no son hombres yl*s trans no son ni hombres ni mujeres. De acuerdo con sus palabras: "[S]i Wittig ha sido recuperada por las multitudes queer es precisamente porque su declaración 'las lesbianas no son mujeres' es un recurso que permite combatir por medio de la des-identificación la exclusión de la identidad lesbiana como condición de posibilidad de la formación del sujeto político del feminismo moderno (2003 [en línea]). 
prácticas escénicas que se realizaron en el Centro Cultural Rojas en el marco de las actividades del Área de Tecnologías de Género. En el periodo 2007-2014, con un claro posicionamiento cultural en relación a un corpus de artistas desobedientes y de sus marcos de legibilidad, se diagramaron las presentaciones de lanzamiento de la revista y otras actividades para poner en funcionamiento una maquinaria crítica capaz de disputar el sentido político de la construcción de las corporalidades en escena. El corpus de artistas que participó de dicha programación constituyó una resistencia a los imaginarios cristalizados entorno a las travestis (vinculadas tradicionalmente al trabajo sexual y a la figura de la vedette despampanante), al tiempo que instituyó una contra-afirmación identitaria de sus propios devenires. A través de estos pliegues, se diagrama un recorrido sexo-genérico desobediente de artistas que participaron en la década del ochenta, noventa y el nuevo milenio en el Centro Cultural Rojas y cuyos trabajos dialogaron con el movimiento social de las travestis de la ciudad de Buenos Aires.

Dicho corpus está conformado por Batato Barea, quien en las salidas de las murgas del carnaval porteño junto con Fernando Noy, conoció a Klaudia con K, Carmen Castagnaro, La Pochocha y Lizzie Yohai y las invitó a participar en sus espectáculos. Tanto Fernando Noy como Klaudia con K participaron del engrudo -tal como Noy llamaba al under de la década del ochenta- que continúo en el Centro Cultural Rojas y en otros espacios autogestionados de la ciudad de Buenos Aires en el nuevo milenio.

En la década del noventa, Mosquito Sancineto integró la programación escénica del Rojas y comenzó a desplegar su devenirandrógino. ${ }^{2}$ Asimismo, el Match de improvisación (espectáculo performático co-dirigido con Ricky Behrens) contó con la participación de Peter Pank y la mencionada Klaudia con K, como porristas de la competencia escénica.

En el nuevo milenio, las actividades organizadas por el Área de Tecnologías de Género consistieron en las presentaciones de El Teje. Primerperiódico travesti latinoamericano. Entre estas, se convocó a Julia Lagos, Dominique Sanders, Fernando Noy, Julia Amore y Naty Menstrual para el lanzamiento de la revista (2007); en la segunda presentación (2008), Marlene Wayar mantuvo un diálogo público junto a Malva Solís acerca de su trayectoria de vida; en la tercera (2008), participó Susy Shock y los Talkin'to Machines (la banda de las varietés teatral Las Noches Bizarras); para la conmemoración de los 25 años del Rojas (2009), Julia Amore (con su unipersonal Solas) y Camila Sosa Villada (con Carnes Tolendas. Retrato escénico de un travesti) participaron de la programación escénica de los festejos de aniversario. En la última presentación de El Teje (2012), Lukas Avendaño (México) estableció una relación entre el activismo muxe mexicano y el movimiento travesti local a través de Réquiem para un alcaraván, a la que se sumó una entrevista que Marlene Wayar le realizó finalizada la performance; por último, en los festejos de los 30 años del Rojas (2014), nuevamente se convocó a Susy Shock, en esta oportunidad, con su espectáculo musical Poemario TRANS-pirado y la banda Talkin'to Machines, como telonera del evento.

Este corpus de artistas configura una cartografía teatral mediante la cual se puede considerar al sur como locus de enunciación (Cfr. Micropolíticas de la desobediencia sexual en el arte, 2016). Sin embargo, para el diseño de este recorrido sudaca, las fronteras geográficas no constituyen un dispositivo limítrofe capaz de ofrecer una mirada sobre un territorio particular. Por el contrario, este mapeo se fue creando a través de la liminalidad poético-política que fueron instituyendo las trayectorias vitales y las prácticas escénicas, de los territorios subjetivos que estas hicieron emerger. Asimismo, dado que estas prácticas escénicas propusieron devenires des-identitarios no regidas por una estética, poética o modalidad teatral común, se las agrupará bajo la categoría de deformances (tal como Naty Menstrual, en diálogo personal, definió
2. La distinción entre travestis y andróginos realizadas proviene de la autodesignación de los/as mismos/ as performers de acuerdo con sus declaraciones. No me interesa establecer de modo taxativo tales categorías, pero si intento resaltar el cuestionamiento de las categorías de género bajo la figura que emerja, sea travestismo o androginia. 
su trabajo). La misma opera de manera contra-productiva para inscribir el trabajo de Batato Barea, Fernando Noy, Klaudia con K, Mosquito Sancineto, Susy Shock, Dominique Sanders, Julia Lagos, Malva Solís, Naty Menstrual, Camila Sosa Villada, Julia Amore y Lukas Avendaño quienes participaron en el Rojas entre 1984-2014. Para indagar el marco institucional que hizo posible sus incursiones performáticas, se ofrece un breve panorama historiográfico del espacio cultural de la Universidad de Buenos Aires.

\section{El Rojas, un laboratorio cultural para acercar la Universidad al pueblo}

En la década del sesenta, el edificio de la Universidad de Buenos Aires ubicado en Corrientes 2038 fue sede de actividades artísticas, entre ellas, las puestas del Grupo de Egresados del Instituto de Teatro de la Universidad de Buenos Aires. No es nuestro objetivo aquí reparar en la existencia del teatro universitario de la Universidad de Buenos Aires, no obstante, no se pueden dejar de mencionar las experiencias previas desarrolladas en el edificio del Centro Cultural Rojas. ${ }^{3}$ También allí radicó la biblioteca de la Facultad de Psicología, distintos centros de estudiantes y la Dirección de Cultura de la Universidad de Buenos Aires, espacio del cual dependió el grupo de Teatro Universitario de Buenos Aires (TUBA) entre 1974-1983, cuya dirección escénica estuvo a cargo de Ariel Arturo Quiroga (Cfr. Ugarte, 2014). El periodista y gestor cultural Mariano Ugarte en Antes del Rojas ¿Qué? (2014) realizó una extensa investigación acerca del Teatro Universitario de Buenos Aires (TUBA). Un especial interés resultan los derroteros que debió atravesar Ariel Quiroga (director del TUBA) en tensión y confrontación con quien dirigía la Dirección de Cultura, Carlos Eduardo Salas (1974-1982). Asimismo, si bien el trabajo de investigación da cuenta de la gran concurrencia y participación del alumnado de la Universidad a los talleres y realización de los espectáculos, pone en evidencia el desinterés de las gestiones de la Dirección de Cultura (a Salas lo continua Jorge Luis García Venturini entre 1982 y 1983) para acompañar tal actividad. Mediante testimonios ofrecidos por los integrantes del TUBA, Ugarte también señaló la visión de Ariel Quiroga de lo que aquel espacio podría representar en términos de gestiones institucionales más amplias para el desarrollo de la cultura al interior de la Universidad de Buenos Aires. Entre estas, sus ambiciones radicaban en crear un amplio programa teatral e inclusive proyectar un centro cultural en el edificio. Luego de nueve años de embates por una actividad escasamente reconocida por las gestiones de la UBA y tras un fuerte impacto emocional que atravesó Quiroga (el director del TUBA) por el fallecimiento de su madre, en el nuevo escenario político de la apertura democrática, desiste en continuar todo tipo de proyecto cultural en la Universidad de Buenos Aires.

Con tales antecedentes, hacia la década del ochenta, el edificio contaba con espacios (aunque precarios y derruidos) para la realización de actividades culturales, entre ellas, la sala principal (actualmente llamada Batato Barea) y la sala Cancha. Precisamente, en este espacio cultural emergente en la apertura democrática, se incrementaron las actividades artísticas realizadas en el marco de la Dirección de Cultura de la Universidad de Buenos Aires. Entre estas, la actividad coral (aunque se desarrollaba de modo independiente en distintas Facultades de la Universidad), carecía de una coordinación institucional; por ello, en marzo de 1984, se creó el Coro de la UBA, bajo la dirección artística de Oscar Castro y Graciela Taquini. De acuerdo con sus palabras:

Cuando iniciamos nuestra actividad, donde hoy es el Rojas existía un olvidado edificio semidestruido de la UBA. Fuimos los integrantes del Coro quienes sugerimos al Rector Francisco Delich y a la Secretaria de Extensión Universitaria de ese momento, Laura Mussa, que ese local, en plena calle Corrientes, si se refaccionaba,
3. Yanina Leonardi y Lorena Verzero (2008) señalan que, bajo la órbita de la Dirección de Cultura de la mencionada institución, entre 19711974, en la Facultad de Medicina, funcionó la Escuela de Mimo Contemporáneo, dirigida por Alberto Saba. La misma fue clausurada (abruptamente) por el Gobierno de María Estela Martínez de Perón. 
podría ser el centro cultural universitario. Felizmente se ocuparon inmediatamente del tema y el Rojas se inauguró en septiembre de 1984, con un concierto del Coro de la UBA (Castro y Taquini, 2009: 77)

Dado que el contexto socio-político demandaba crear nuevos canales que restituyan el valor de la expresión y espacios para el desarrollo cultural, con el expreso objetivo de centralizar y preservar la calidad de las actividades artísticas que promovía la alta casa de estudios, se fundó el Centro Cultural Rector Ricardo Rojas bajo el expediente $\mathrm{N}^{\circ} 30.304 / 84$. A lo largo de sus treinta años de funcionamiento (1984-2014), el Rojas fue una usina cultural y un laboratorio de experimentación y renovación artística.

En sus comienzos, el Centro Cultural Rector Ricardo Rojas dependió del Área de Extensión Universitaria de la Universidad de Buenos Aires, motivo por el cual las políticas de gestión desarrolladas se caracterizaron por "acercar la universidad al pueblo", a la sociedad, tal como aseveran los principales propósitos fundacionales del área de extensión en los espacios universitarios. ${ }^{4}$ No obstante, de acuerdo con el primer director del Rojas, Lucio Schwarzberg (Director de Cultura de la UBA entre 1984-1986), quienes se embarcaron en la tarea inaugural de generar un centro cultural estatal una vez culminada la dictadura, más que un programa o perfil de gestión institucional, tuvieron realmente entusiasmo y deslumbramiento frente a la posibilidad de trabajar con entera libertad (Cfr. Schwarzberg, 2009). Con este ímpetu comenzaron a planificarse actividades mediante las cuales el Rojas llevó adelante una programación de cursos, capacitaciones, diálogos, conferencias y una programación artística con rasgos diferenciales en relación con otros centros culturales de la época, entre ellos, el San Martin, caracterizado por un perfil "más rígido" o el Centro Cultural Recoleta, "más paquete" como señaló el mencionado Lucio Schwarzberg (2009a: 18). La tarea fue posible ya que, por entonces, existía una gran confianza de intelectuales y artistas hacia el Estado:

En ese momento se lo podía pedir a la gente que viniera a trabajar para el Estado gratis. Era reconquistar un Estado que había estado en manos de los militares y sus secuaces. Ahora sabemos que no hay por qué trabajar gratis para nadie (2009: 12).

De esta manera, en medio de los escombros de una oscura época que había signado y cercenado el campo cultural, el Rojas ofició de puerta de entrada para quienes comenzaban a salir de las catacumbas y quienes volvían del exilio. Al respecto, Schwarzberg agrega: "El grueso de ellos no cobraba, venían porque había que ocupar el espacio (...) Nos proponíamos instalar temas que habían estado fuera de la academia" (2009a: 18). Con esta propuesta comenzaron los encuentros con intelectuales y artistas. Según Tamara Kamenszain, Directora de Asuntos Extracurriculares del Rojas desde su fundación hasta 1990, la apuesta consistió en desarrollar un movimiento dinamizador hacia el interior de la Universidad al brindarle al alumnado una relación viva, no heterodoxa, libre con la cultura y sus productores, más allá de lo que le ofrecían los marcos teóricos de sus carreras. Y un movimiento hacia el exterior de la Universidad, es decir, establecer una nueva vía de contacto con el público extrauniversitario a través de un saber académico ofrecido de manera no convencional (Cfr. Kamenszain, 2009). Entre estos encuentros, destaca Daniel Molina:

Uno de los hechos memorables de los tiempos heroicos fue la realización de la primera conferencia que el filósofo Jacques Derrida dictó en la Argentina. El que por entonces era el pensador más influyente del mundo no sólo no cobró honorarios (que hubieran sido imposibles de pagar), sino que además aceptó costearse su propio pasaje. A cambio de su colaboración desinteresada, el Rojas le gestionó un encuentro con Borges [(1899-1986)]. Entre los asistentes estaban Enrique Pezzoni, Josefina Ludmer, Beatriz Sarlo, Ricardo Piglia, Alan Pauls, Nicolás Rosa y Jorge Panesi (2009 [en línea]).
4. La Universidad de Buenos Aires (UBA) fundó el Área de Extensión Universitaria a mediados de la década de 1950. Para ello, adoptó los genuinos propósitos ya implementados por dichas áreas en otras universidades luego de la reforma universitaria (1918) cuando se crean tales espacios al interior de las altas casas de estudios. En este sentido, "integrar la Universidad a su contorno social" fue uno de sus principales objetivos, para ello se realizaron actividades para incluir sectores más amplios de la sociedad y abordar complejas problemáticas sociales. En el primer aniversario del área de Extensión Universitaria de la Universidad de Buenos Aires, se destacan la creación del 1) “Centro de Desarrollo Integral de la Isla Maciel", 2) ciclos radiales y 3 ) reactivación de una biblioteca popular para la realización de actividades culturales. Todas estas acciones, aunque fueron pruebas piloto, resultaron altamente positivas para la continuidad del área (Departamento de Extensión Universitaria, 1957). 
Con este espíritu, el Centro Cultural Rojas sostuvo ciclos memorables, entre los cuales restituye Kamenszain:

Iniciamos dos ciclos históricos: "La que se viene" y "Los que conocieron a" (...) El primero sirvió para darle la palabra a las nuevas camadas literarias (Pauls, Caparrós, Guebel, Chitarroni). El segundo ciclo fue una opción heterodoxa para el concepto de homenaje. Cuando hicimos "Los que conocieron a Alejandra Pizarnik" pasó algo que, sin exagerar, aportó la clave para que el Rojas entrara en una nueva etapa. Cuando estaba por terminar el evento, un tímido adolescente del que sólo llamaban la atención -para lo que se usaba en esa época- los extraños reflejos oxigenados en el pelo, me pidió permiso para recitar unos poemas de Alejandra. Acto seguido, nos dejó a todos boquiabiertos con una intervención que ponía la lectura de poemas a años luz de lo que se había hecho hasta entonces. Era Batato Barea. Desde ese día el under se instaló en el Rojas para siempre (en Jiménez, 2009 [en línea]).

En 1986, con la incorporación al Área de Letras de Daniel Molina, comenzó el ciclo Lengua Sucia (poesía para después de todo). El ciclo se desarrolló entre 1986 y 1991. El mismo Molina (2009) señala que el fin del ciclo coincidió con la culminación de una etapa del Centro Cultural Rojas. Asimismo, el 6 de diciembre de 1991 fallece Batato Barea, fecha que marca un hito en la finalización de una época la cual había comenzado bajo el manto de la transición democrática y -ya en el menemato- el contexto político social ofrecía otros signos para caracterizar la década del noventa. En este ciclo se presentaban grupos extranjeros y bandas de rock, moda y poesías. Como su nombre lo indica, se trataba de actividades que, desde los márgenes de una reconocida institución -en palabras de Tamara Kamenszani (en Jiménez, 2009)-, se enchastrara y ensuciara el campo cultural heredado de la dictadura. Paralelamente al comienzo del ciclo, el Área de Teatro había desestimado las propuestas de Batato Barea "por parecer demasiado under, o quizás por parecer directamente indemostrable", como sugiere María Moreno (2003 [en línea]). Sin embargo, dado que el detritus en los ochenta operaba como un dispositivo de (re)invención performática de modos de hacer que la cultura mainstream (hegemónica) desechaba, mediante alianzas marginolientas Barea fue invitado a presentar sus espectáculos de poesías performáticas (Garbatzky, 2013) en el ciclo creado y organizado por Daniel Molina, quien restituye:

Mientras él [Batato] vivió, a la mayoría de la gente de teatro -incluso a los más audaces- le parecía, en el mejor de los casos, un sapo de otro pozo. Yo le ofrecí que basara sus nuevos trabajos en textos poéticos y así podría sumarlo al ciclo de poesía Lengua Sucia. De esa forma surgieron sus mejores obras: desde Alfonsina y el Mal hasta La Carancha, una dama sin límites (en la que compartió cartel con Alejandro Urdapilleta y Humberto Tortonese), pasando por Un puré para Alejandra. Si Batato hubiera llegado al Rojas unos años más tarde, cuando se sumaron al área teatral gente como Rubén Szchumacher, Vivi Tellas, Alejandro Tantanian, Rafael Spregelburd, Andrea Garrote, Daniel Veronese, Miguel Pittier o, ahora, Matías Umpiérrez, quizá la historia hubiera sido diferente, pero hasta su muerte fue más un "clown travesti" que un "actor" (2009 [en línea]).

En 1989 se creó la Galería del Rojas, bajo la dirección curatorial de Jorge Gumier Maier, con la instalación de Liliana Maresca Lo que el viento se llevó. La cochambre. Batato Barea intervino la inauguración con una performance poética, que consistió en la lectura de Sombra de Conchas, un texto neobarroco de Alejandro Urdapilleta plagado de figuraciones sexualizadas y remisión a un escenario desobediente de conchas y braguetas travisteriles. El texto completo publicado en Vagones transportan humo dice: 
Sombras de concha/ Conchas con olor a teatro/camarines con olor a concha/ ¡conchas! ¡conchas!/ breteles de corpiños y caireles/copa va copa viene/ el bulto magno que me enceguece/ desde tu entrepierna almibarada/gloria de tu bragueta/ parsimonia de transeúntes/carroña que masco/y leche/ y al final telones/y centinelas/ pelucas de pétalos/ alas de cuarzo/ bambalinas en el alma/ rímel en el culo/ 130 putos frente a un espejo/todos descuartizados/vocación de concha/ iconchas! ¡conchas!/ libre albedrío/ y una montaña/y atrás el fuego/ y la huella de tu chupón en mi nalga cruda/ medialuna de árabes/ matanza de chinos/ saqueos de fiambrerías/ 4 conchas que arrastro con mi changuito/ más 5 que llevo puestas/ son 9 conchas/ leche condensada/ pan lactal/ y esperma/ como un pulpo esa concha enorme/ se va acercando/ ya cubre todo el Parque Lezama/ iconchas! iconchas!/ Potras de crines blancas/ cayendo en los precipicios/ iconchas! iconchas!/ Cisnes que alzan vuelo/ y escupen sangre desde las nubes/ conchas que se derriten/ conchas ruborizadas/ conchas famosas/ ¿concha peluda?/ ponele spray/y atrás de todo mi muerte negra/ dientes de raso/ pestañas grises/ aplausos para las conchas/ ¡viva vítores y clarines!/ aplausos para el deseo/ como una baba/ aplausos para la luna que tiene concha/ aplausos para el becerro/y el vellocino de oro/y para tu concha/ tan elegante/ tu concha de firmamento/de algarabía/ y de sentimiento/ iaplausos para la concha de tu madre!/ iy para la de T...M...que todavía ruge!/ aplausos para mil conchas de camarines/conchas postizas/ conchas de llantos/ conchas de risa/ conchas que crujen/ conchitas diminutas liliputienses/ y grandes conchones profundos/ ien fin!/ ¡A la Gran Concha Argentina Salud! (Urdapilleta, 2008: 69-71).

De acuerdo con el estudio de Irina Garbatzky (2013), la declamación escénica de Barea respondía a las lecciones de recitado de poesías de los manuales escolares en los que se remarcaba el uso de la voz lenta y baja, pero animada cuando los pasajes del texto lo requieran, con una pronunciación sin defectos, movimientos naturales y una actitud corporal noble y varonil. Esta dramaturgia corporal se contraponía con el vestuario y accesorios propios del universo femenino: túnica blanca larga y tocado en el cabello; un notable y corroído delineado de ojos y grandes anillos y collares (realizados por él mismo). A pesar de este uso vestimentario, Barea no afeminaba su voz; en consecuencia, la performance poética se producía entre una neutralidad corporal conservadora y el desacato de las convenciones de géneros (masculino/femenino).

Por su parte, la instalación de Liliana Maresca estaba conformada por sombrillas, sillas y mesas estropeadas, despintadas y oxidadas, cochambrosas, traídas de lo que fue un glamoroso recreo del Tigre, El Galeón de Oro (intervenido en la dictadura militar y luego abandonado). Como signos y restos de un pasado reciente, la elegía del texto y de este mobiliario y objetos derruidos señalaban lo que el viento se llevó. No obstante, la exposición (tanto en el trabajo de Barea como en el de Maresca) era una afirmación de la transmutación de lo que las sociedades descartan, residuos puestos en la escena de una nueva mirada, objetos que constelan entorno al deseo, para que cada quien pueda vivir más su propia vida (como indica un poema de Liliana Maresca) por fuera de las formas convencionales y tradiciones artísticas (Cfr. Gutiérrez, 2018).5 


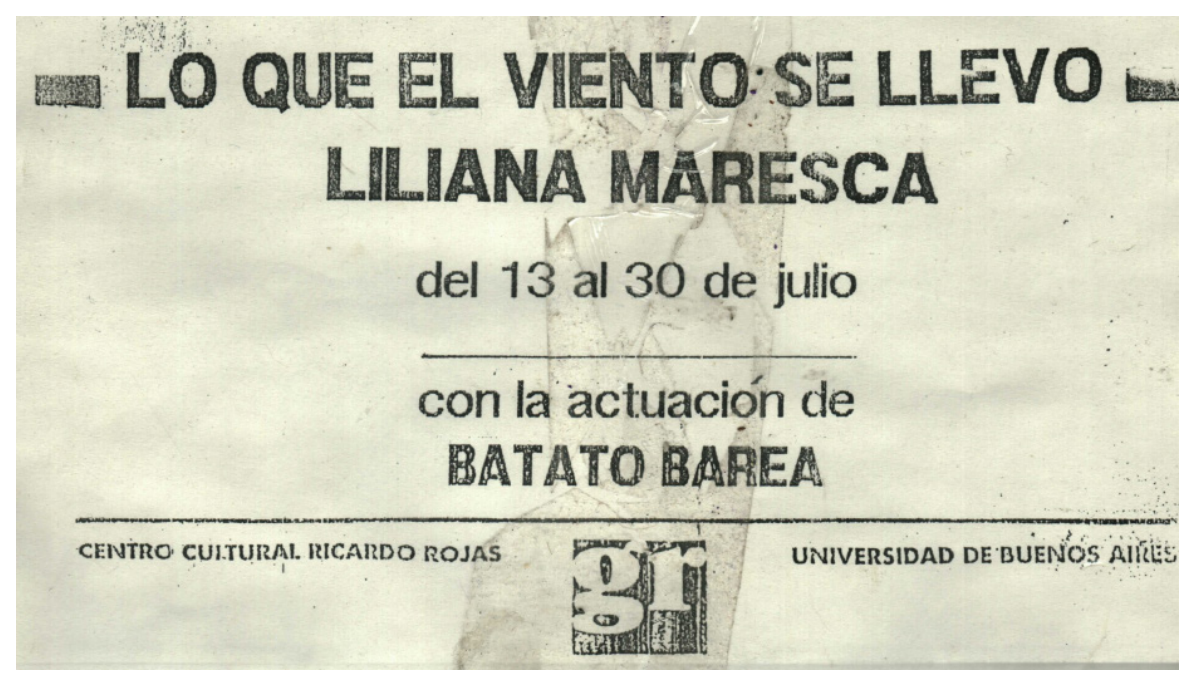

Recorte de afiche de difusión. Lo que el viento se llevó (1989). Centro Cultural Rojas. Archivo: Museo Casa Batato Barea

Por esta exposición inaugural y por el perfil curatorial desarrollado entre 1989-1992 en la galería de artes visuales del Centro Cultural Rojas, Mariana Cerviño (2012) considera que la gestión de Jorge Gumier Maier propuso un corpus de artistas herejes con una doble dinámica en el campo artístico. Cerviño (2012) refiere a artistas que expusieron en la Galería del Rojas y otros/as quienes contribuyeron al diseño curatorial de dicho espacio. Entre los primeros considera a Marcelo Pombo, Pablo Suárez, Miguel Harte y Omar Schiliro. Luego extiende el circulo hacia a Roberto Jacoby, Liliana Maresca, Alfredo Londaibere, Esteban Pagés y Emiliano Miliyo, Feliciano Centurión, Benito Laren. Por un lado, hacia el interior de la institución, estos artistas compartían un habitus común generando afinidades espontáneas, las cuales apostaban a la experimentación colectiva, interdisciplinaria y amateurs de sus producciones, al tiempo que desacataban las normas y valores instituidos en torno de los usos vestimentarios y el orden sexual del régimen dictatorial. Por otro lado, hacia el exterior del campo, se distanciaban de la tradición artística local estableciendo relaciones polémicas. Si bien la socióloga refiere, específicamente, al campo de las artes visuales, se puede considerar la herejía artística de Barea al interior del campo teatral. La misma quedó explícitamente manifiesta cuando el performer recitó el mencionado poema, Sombra de Conchas, en el Centro Cultural San Martín en la condecoración de Niní Marshall como ciudadana ilustre de la ciudad de Buenos Aires el 21 de diciembre de 1989. En aquella oportunidad, la prensa de la época expresó:

De inmediato ocupó el escenario Antonio Gasalla, que interpretó con su habitual gracia y simpatía a Mamá Cora, y luego Batato Barea, un cómico de limitados recursos, puso la nota burda y chabacana en un homenaje que no merecía su presencia (s/d, 1989). 


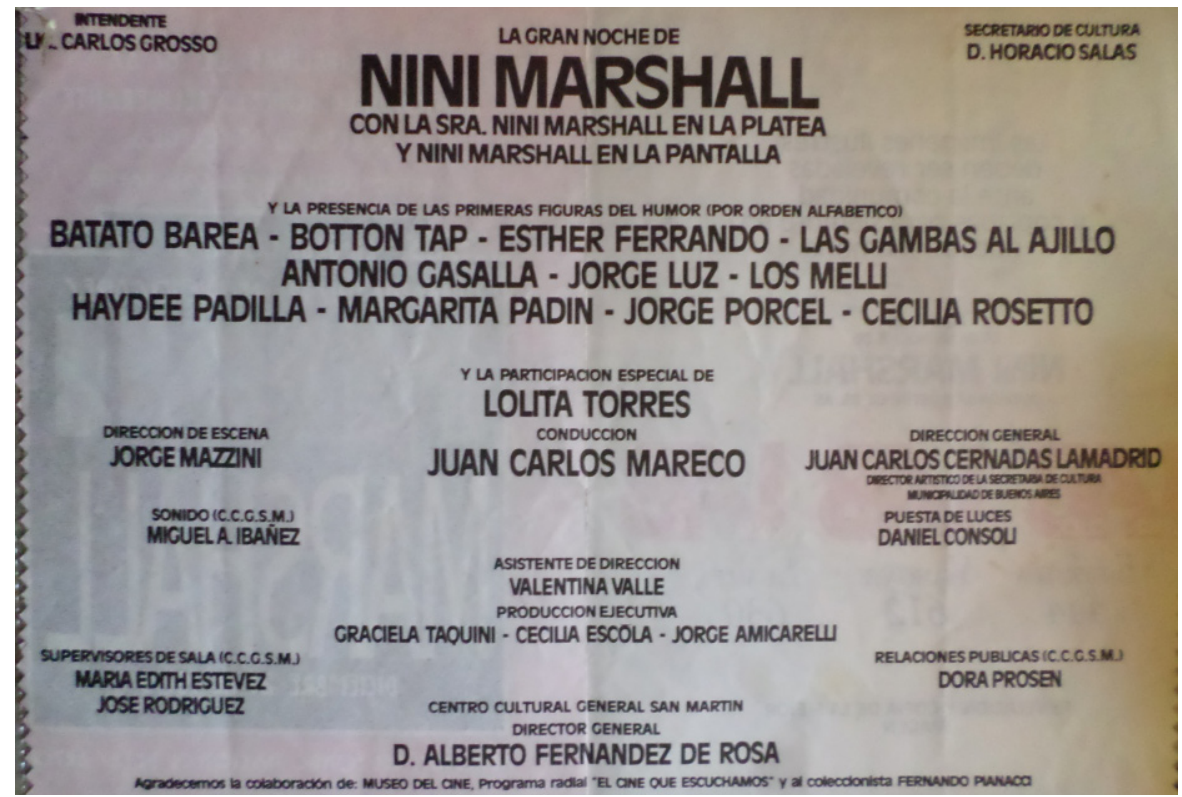

Programa de mano. La gran noche de ciudadana ilustre de Buenos Aires: Niní Marshall (1989). Centro Cultural General San Martín. Archivo: Museo Casa Batato Barea

En este sentido, a pesar del reconocimiento de Barea en el circuito artístico hacia 1989, una misma performance poética podía tener una buena recepción (como fue el caso en la inauguración de la Galería del Rojas), pero causar un escándalo en otros marcos institucionales o resultar censurada como ocurrió en el Teatro Alvear en el mismo año. En relación de este desplazamiento, el mismo Barea señaló:

Lo que les molesta es que yo hago de mí. Que muestro mi propio concepto, mi propia ideología. Una ideología que tiene que ver con la poesía de Noy, de Pizarnik, de Perlongher, que tiene que ver con la realidad de la calle, con lo bajo, con lo marginal, con las prostitutas (en Hojman, 1989: 25).

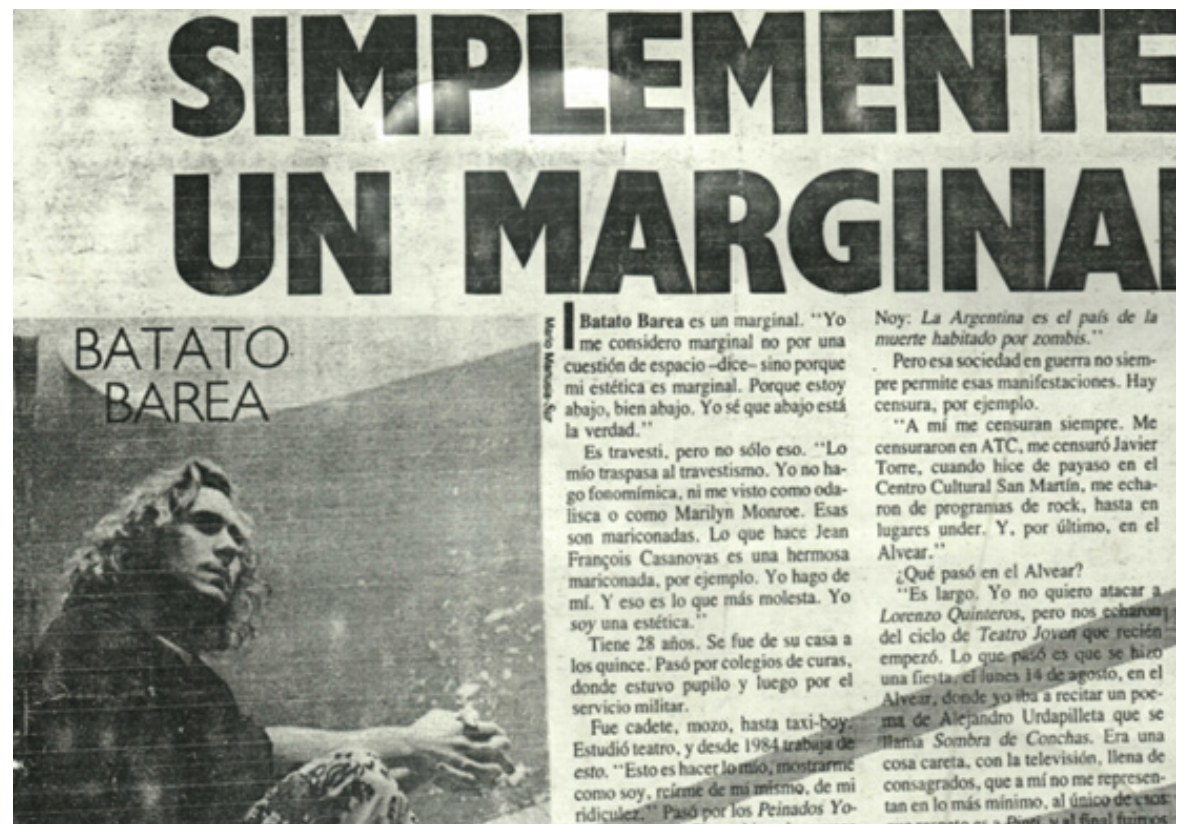

Recorte de nota de prensa. Hojman, E. (9 de septiembre de 1989). "Simplemente un marginal". Sur, p. 25. Archivo: Museo Casa Batato Barea 
Acerca de esta particular aceptación o rechazo de la labor del performer, también se debe agregar que, mientras sus participaciones en el Centro Cultural Rojas con el emblemático Clu del Claun no fueron cuestionadas por producir una poética teatral, aunque disruptiva, inserta en una tradición teatral, por fuera de dicho grupo, sus creaciones desobedecieron formatos escénicos, deviniendo performáticas y tensionaron no sólo el lenguaje de la práctica teatral, sino también las fronteras socio-sexuales de las figuraciones corporales, por lo cual, sus trabajos fueron desestimados para integrar programaciones teatrales oficiales, o inclusive, la del Centro Cultural Rojas como referimos más arriba.

Por lo expuesto, el travestismo escénico de Batato Barea, además de un procedimiento poético, fue una estrategia política irreverente al imaginario social, cuyo patrón de sexualidad moderno (mata puto) se escandalizaba ante el desacato de la norma binaria. De esta manera, a contrapelo de la sociedad, inclusive de determinado sector del activismo sexual con una fuerte impronta liberal (Cfr. Cuello y Lemus, 2016), Batato tejió alianzas con las travestis de las murgas porteñas, a quienes invitó a participar en sus espectáculos de poesías. ${ }^{6}$ Ante un escenario de trans-odio generalizado, nos preguntamos cómo fue posible aquel tránsito sexo-genérico desobediente en los marcos "de una rancia institución como la Universidad de Buenos Aires" (Link, 2009: 254). Las reflexiones de Roberto Jacoby entorno al Rojas, acaso se acercan a una posible respuesta:

El Rojas es un caso ejemplar y probablemente único desde el punto de vista político. Fue un acto de resistencia a la eliminación emprendido por un pequeño grupo de seres sensibles y talentosos, que buscan la belleza en su entorno y el amor en sus amigos, pero más aún, el Rojas instituyó cierta poética que hiciera más vivibles las limitaciones de la enfermedad [VIH-sida], de la pobreza, de la posición subalterna, de la desdicha: en cierto modo inventó su propio mundo, sus propios criterios, por otra parte, muy amplios (en Longoni, 2011: 25).

En consecuencia, en un contexto en el que, a pesar del pleno ejercicio de un estado de derecho, continuaba el amedrentamiento alrededor de determinadas zonas (de ciertos bares) con dispositivos de control por averiguación de antecedentes y las razzias policiales recaían sobre las disidencias sexuales, en el Centro Cultura Rojas, las travestis -bajo la excusa de marcos y códigos escénicos- pudieron circular libremente en un territorio dislocado (Rosa, 2008) que suspendía la persecución y criminalización de sus derivas identitarias. Por lo cual, replegándose a dicho control e inventando sus reglas de juego, el Rojas también formó parte de un circuito de espacios subterráneos, contraculturales o, como el mismo Indio Solari los llamó, guaridas underground para Dionisos. ${ }^{7}$ Si bien esta última caracterización fue utilizada para referenciar espacios surgidos en un contexto cultural en el transcurso del régimen de facto, dado que las travestis fueron sistemáticamente perseguidas "por llevar ropas del sexo contrario" y sin ser ciudadanas, es decir, sujetas [sic] de derechos hasta la sanción de la Ley de Identidad de Género (2012), sus vidas estuvieron azoradas por otro régimen, el heterocisexual. Por lo tanto, creemos oportuno considerar al Rojas como una guarida capaz de darles cobijo a un grupo de personas que, más allá de las binarias categorías de género, en un marco "de una prodigiosa apertura mental, moral y afectiva" (Molina, 2009a: 249), pudieron agenciar trayectorias vitales, tensionando los constructos biopolíticos normativos. Esto fue posible, primero, a través de prácticas poético-escénicas (en la década del ochenta y noventa) y, luego, por las actividades programadas tanto por el Área de Estudios Queer (desde 1997), como por la agenda del Área de Tecnologías de Género, desde el 2005 hasta la última actividad organizada por dicha Área en la conmemoración de los 30 años del Rojas en 2014.
6. Acerca del desplazamiento de las travestis del movimientos de las minorías sexuales de la década del ochenta, véase Nicolás Cuello y Francisco Lemus (2016), investigación en la que se pone de manifiesto las divergencias entre el GAC y la CHA publicada en la revista №1 de Sodoma, en la que se cita: "Ciertos grupos gays al organizar una fiesta rechazaron la posibilidad de un show de travestis. Debía ser una fiesta 'seria', dijeron. Al ser invitados a un programa radial uno de ellos se autoexcluyó por el timbre agudo de su voz y su modulación femenina. Cuidar la imagen frente a los otros. No ser locas sino tratar de ser 'naturales'. No 'ofender' con nuestra conducta o apariencia. De eso se trata. Algunos gays están contentos porque "no se les nota"' (Jorge Wildmer o Mirna de Palomar o Lic. Raquel Guatraimen, 1984:11).

7. La caracterización de los sótanos y catacumbas como guaridas del under que comenzaron a funcionar en los últimos años de la dictadura cívica-militar como resistencia contracultural a la censura normativa fue realizada en el marco de la entrevista realizada por Daniela Lucena y Gisela Laboreau (en 2011) a Carlos "Indio" Solari, la frase completa dice: "Un artista está obligado a surfear sobre las olas terribles de las cosas que ocurren y que pueden hacer intolerable la vida (...) Durante la dictadura militar fue necesario construir guaridas underground para Dionisios. Tratar de que el miedo no nos paralizara y el amor no fuera desacreditado. Que siguiera operando como el simple deseo del bien para otro. Que la alegría no fuera parodiada y que la belleza apareciera aunque más no fuera esporádicamente" (en Lucena, 2013 [en línea]). 
Asimismo, aunque en la década del ochenta, estas actividades tuvieron como protagonista a Batato Barea, se debe advertir una trama de complicidades entre distintos agentes culturales que allí trabajaron. Entre ellos, resulta crucial la figura de Leopoldo Sosa Pujato, director del Centro Cultural Rojas entre 1986-1993. En palabras de su antecesor, Lucio Schwarzberg: "Fue él que realmente le dio el perfil. Él había venido en 1984 de España, donde había vivido el 'destape'. Por eso probablemente, su decisión de incorporar a las minorías y las "tribus urbanas"' (2009b: 24). Por su parte, Beatriz Sarlo (2009) también relaciona la movida madrileña con el espíritu juvenil e innovador que se desarrolló en los años de transición democrática en la ciudad de Buenos Aires y, particularmente, en el Centro Cultural Rojas.

Además, el impacto producido por el Rojas en el campo cultural del ochenta se puede comparar con el Instituto Di Tella en la década del sesenta, ya que, al igual que este último, el Rojas fue un underground institucionalizado (Massota en Pinta, 2013: 23), cuyas propuestas contrastantes con un medio caracterizado por un canon tradicional no podrían dejar de ejercer presión en sus contextos de recepción. Sin embargo, tal como Beatriz Sarlo (2009) indica, entre ambas instituciones existe un abismo, ya que el Di Tella produjo sus actividades bajo financiación privada y el Rojas se sostuvo mediante presupuesto estatal. Por otro lado, mientras que la primera institución respondía a un núcleo programático de artistas, curadores y funcionarios, por el contrario, el Rojas se fue haciendo sobre la marcha, a través de afinidades y alianzas. $\mathrm{Al}$ respecto, Daniel Molina señala:

Una mirada a estas dos décadas que estuviera muy atenta al presente puede llegar a esconder la sustancia. Muchas de las cosas que se hacían por entonces surgieron sin ningún plan. Es más, creo que las transformaciones más profundas, las que fueron definiendo un perfil valioso, no tuvieron ningún grado de predeterminación. Leopoldo [Sosa Pujato] arribó a la dirección del centro como una forma de castigo. Había estado en la dirección del, por entonces, recientemente creado Ciclo Básico Común (que, con sus noventa mil alumnos, era el niño mimado de la universidad) y por sus diferencias con rectorado fue expulsado de allí y nombrado director del Rojas, una dependencia que nadie sabía ni donde quedaba (2009a: 252).

Si bien pueden resultar infinitas las anécdotas de la institución acerca de la capacidad de gestión en precarias condiciones presupuestarias (cuestiones que, hasta el día de hoy, como se puede advertir con la experiencia del El Teje. Primer periódico travesti latinoamericano, constituyen una problemática de la Universidad de Buenos Aires capaz de desarrollar proyectos institucionales de alto nivel de contenido, pero difícil de sostenerse sin expresa voluntad política que garantice la continuidad de los mismos a causa de la falta de fondos económicos) es innegable que, a lo largo de los años, el Centro Cultural se caracterizó como un laboratorio de política cultural, un espacio en el que se desarrollaron proyectos artísticos novedosos y experimentales, los cuales no estuvieron exentos de errores y equivocaciones. Si bien distintos agentes posibilitaron dicho perfil, uno de sus promotores más importantes fue, como ya señalamos, Leopoldo Sosa Pujato, quien consideraba que:

En realidad, en la Argentina (...) no hubo una producción subterránea fuerte. La dictadura había debilitado las posibilidades de producción: uno sacaba una tapa y no había nada. Nuestro intento, entonces, es crear situaciones y las condiciones que permitan que sectores sociales marginados del poder puedan generar lenguajes propios, construir un protagonismo fuerte (en Pacheco, 1992: 2).

De acuerdo con este posicionamiento y frente a la necesidad de crear un ámbito de libertad para jerarquizar al actor social, la gestión del emblemático director del Rojas 
posibilitó los marcos de un espacio desprejuiciado (Lebenglik, 2009), el cual se convirtió en un referente para la innovación o semillero artístico (Vázquez, 2009). Tal política cultural de extensión social propició modalidades artísticas de travestismo escénico, en las que fue posible interrumpir la ficción somatopolítica (Preciado, 2003), es decir, la forma dominante que despliega el orden mayoritario para normalizar, de modo biopolitico, los procesos de subjetivación.

En este sentido, aunque en el Centro Cultural Rojas no existió un dispositivo curatorial cuyo fundamento proponga cruces poéticos sexo-genérico disidentes en la escena teatral, dada la política cultural llevada a cabo por la institución, se generó un espacio de (re)presentación minoritaria, como instancia de resistencia, visibilización y autoafirmación de trayectorias vitales travisteriles que se posicionaron en el campo cultural de la ciudad de Buenos Aires entre 1984-2014. De acuerdo con esta perspectiva, este aspecto fue realizado, de modo paradigmático, a través de la labor artística de Batato Barea y los homenajes que le brindaron a su figura, entre estos, desde 1999 la sala principal lleva su nombre. En el nuevo milenio, la programación del Área de Tecnologías de Género recuperó su trabajo diseñando una genealogía artística cuestionadora de las categorías de género. De esta manera, considerando a Batato Barea como un eslabón semiótico (Deleuze y Guattari, 2002), en el Centro Cultural Rojas se puede trazar una cartografía teatral conformada por artistas quienes, a través de sus prácticas escénicas, desarticularon de modo manifiesto la cis-normatividad, entre ellos/as: Fernando Noy, Klaudia con K, Mosquito Sancineto, Julia Amore, Naty Menstrual, Dominique Sanders, Camila Sosa Villada, Lukas Avendaño y Susy Shock. Dicho corpus de artistas no respondió precisamente a una planificación cultural a desarrollar; por el contrario, como tantas de las actividades del Rojas, este mapa teatral se fue generando por las motivaciones de quienes participaron de las gestiones y de las distintas áreas del centro cultural.

Por su parte, el testimonio de Paula Viturro (2009), ofrecido en los 25 años del Rojas, manifestaba que uno de los mayores desafíos del Área de Tecnologías de Género que coordinaba consistía en no volverse en un área gueto de la institución. Felizmente, Viturro encontraba que la programación artística del Centro Cultural había desarrollado una impronta queer gestionando e impulsando una serie de actividades atravesadas por un dispositivo de cuestionamientos a los patrones de normatividad sexo-genérica. Entre ellas:

[E]l área de danza estrena tres obras bajo el lema Queer Dance. El área de Letras no solo presenta un libro en el que se tensan cuestiones referidas a la diversidad sexual y étnica en el contexto latinoamericano, sino que además convoca al artista performer Dani Umpi, quien ofrecerá un show que promete rarezas y más. Por su parte, el área de Teatro inaugura un intercambio con el Festival Escena Queer y el teatro El Cubo, a través del auspicio de un Ciclo de Musicales dirigidos por Nicolás Pérez Costa, el cual funcionará como antesala del 2do. Festival de la Escena Queer en noviembre de 2008 (Viturro, 2009: 228).

Originalmente, el texto que aquí citamos de Paula Viturro, "Orgullo por partida doble," fue publicado en La hoja del Rojas en noviembre de 2007. El primer Festival de la Escena Queer se realizó entre el 11 y 13 de noviembre de 2005 en el teatro El Cubo de la Ciudad de Buenos Aires, producido por Monina Bonelli, Maruja Bustamante y Florencia De Angelis. El mismo tenía como objetivo aportar una mirada sobre la cultura queer a través del trabajo de "artistas que exponen la diversidad, la exacerbación del cuerpo y la desmesura frente a la norma. Una provocación a la idea de rareza y normalidad". Para ello las modalidades artísticas fueron diversas, entre ellas: las prácticas escénicas (teatro y performances); música, la indumentaria y las 
artes visuales. En este primer evento se homenajeó a María Muscari y se entregaron los Queer Awards 2005 a personalidades de la cultura queer (Alejandro Urdapilleta; Barby; Belén Blanco; Celeste Carballo; Dani Umpi; Fernando Noy; Fernando Peña; Florencia de la V; José María Muscari; Liliana Felipe; Marcia Amoroso; Mosquito Sancineto; Peter Pank; Roberto Piazza; Walter Soares de Caviar). La programación consistió en: Warm up musical, DJ Doom (Bariloche); Anfitriona: Purpurina por Iven (Uruguay) y Alma PIÑIN Holgado; Retrospectiva de José Maria Muscari, homenaje coordinado por Ana Durán; Dj set a cargo de DJ Silvio Rech (La Pampa), DJ Adrián Orellano (Córdoba), DJ Solxie, DJ Fabián Jara, DJ Doom (Bariloche), DJ Andy Arias (La Pampa); SADO BP (performance/bodypainting) con make up de Esteban de Marco y Aymará Abramovich como modelo; El año del Lewerburst de Cristian Morales; Minuto queer con Mosquito Sancineto como anfitrión; performance poesía y música a cargo de Not Poett + DJ Novella; Insectos con diseño de vestuario de Ale Baamonde y música de DJ Novella; Nancy Doméstica de Mariana Nadaja- Lali BalbiNatalí Tentorí; Tumbamores; Cecesrock con Celeste Carballo y banda; Homorama de Hernán Morán; Desfile Bossini Pithod; Kabaret Elektro Pank por Peter Pank; Marito Filgueira (performance); Revista Vago con Christian Dios - Charly Darling-Vogue - Isis (performances y proyecciones); Música de Machine Marafiotti, Ambar, Blitto, Gray, Dani Umpi (Uruguay) con estrella invitada: Gaby Vex; Desfile Militancia Homo + Prana, con indumentaria: Militancia Homo y peluquería de diseño de Prana; Jem er the Holograms de Fede Castellón y elenco; Esta vez no voy de Cecilia Rainero; Adivina con Maisa Pereyra- Handruma Mason- Rosana Montenegro; El homosexual (o la dificultad para expresarse) de Copi por el grupo Humoris Dramatis; Réquiem Nupcial de y por Marta Pacamicci; 4200 Vacas (Uruguay) de Agösto; Veladas Temáticas por Grupo Mondopasta. Información disponible tomada de: http://www.alternativateatral.com/evento304-i-festival-de-la-escena-queer).

En consecuencia, se puede observar que el Rojas desarrolló una gestión que, aun sin ser prevista o reconocida por las distintas direcciones institucionales y coordinaciones de las áreas, estuvo en concordancia con los objetivos del área de extensión universitaria desarrollando un perfil cultural innovador proyectado hacia la sociedad. Asimismo, aunque desde el año 2002, el Rojas depende de la Secretaria de Relaciones Institucionales, Cultura y Comunicación, bajo la órbita presupuestaria de Rectorado de la Universidad de Buenos Aires, es decir, ya no pertenece al marco institucional de extensión universitaria, su carrera continúa amparándose en el Estatuto Universitario que garantiza la difusión de las actividades académicas y culturales hacia la sociedad, principalmente, para quienes la universidad no es un horizonte posible. De esta manera, a través de sus fundacionales propósitos de extensión universitaria, las distintas gestiones que coordinaron el espacio -con sus momentos de mayor o menor apogeo- asumieron el complejo compromiso social de comprender y transformar la realidad. Al respecto, Jorge Dubatti señala: "el Rojas es un espacio de encuentro, de reunión, de identidad. Importa especialmente que se trate de un espacio de la Universidad de Buenos Aires que se abre a la sociedad más allá de lo estrictamente académico" (2009: 267).

Tal como hemos mencionado, dado el complejo perfil institucional del Rojas, allí fueron posibles distintas plataformas y dispositivos disidentes al régimen de verdad instaurado por las tecnologías de la heterocisexualidad obligatoria. A través de estas instancias, es posible diseñar una cartografía teatral de las desobediencias sexo-genéricas y, si bien esta no tiene carácter de completud -por el contrario, se caracteriza por su discontinuidad- su recorrido ofrece nodos establecidos a partir de trayectorias poético-políticas en un contexto particular cuando se gesta El Teje. Primer periódico travesti latinoamericano en el Centro Cultural Rojas. A continuación desarrollamos consideraciones acerca de dicha cartografía teatral. 


\section{¿Cuál sería la particularidad de una cartografía teatral desobediente?}

La dificultad real, pero también el proyecto más audaz, más original de la teoría feminista sigue siendo precisamente ese: cómo dar forma teórica a esa experiencia, que es a la vez social y personal, y como construir al sujeto femenino a partir de esa rabia intelectual y política.

(De Lauretis, 1992: 263)

Los mapas teatrales se han configurado de acuerdo con límites geográficos capaces de gestionar distinciones en base de áreas, regiones, naciones, continentes, etc., es decir, a partir de una teoría territorial de los fenómenos teatrales (Cfr. Dubatti, 2008). Sin embargo, la cartografía teatral de las desobediencias sexo-genéricas que aquí interesa atender se conforma en tanto cartografía crítica ya que "Los mapas tradicionales no incluyen la subjetividad de los procesos territoriales, las representaciones simbólicas, y los imaginarios sobre los mismos, y la permanente mutabilidad a la que están expuestos" (Risler y Ares, 2013:78). En este sentido, "a vuelo de pájaro" -tal como concibe la tarea del cartógrafo el proyecto Iconoclasista, fundado en 2006 por Julia Risler y Pablo Ares, en cuyo marco desarrollan investigaciones colaborativas en base de tres dimensiones: artística, política y académica- (2018 [mimeo]), el mapeo del corpus de artistas que se propone, contempla los territorios como disputas de poder, tensiona los oficiales y complejiza el entramado en su dimensión social y diseño una cartografía de devenires de subjetivación travesti a través de prácticas escénicas-performáticas.

Considerando este último aspecto, se debe advertir acerca del riesgo de capturar y cristalizar las trayectorias vitales que la integran ya que, siguiendo a Félix Guattari, "Toda vez que una problemática de identidad o de reconocimiento aparece, estamos frente a una amenaza de bloqueo y de paralización del proceso" (en Perlongher, 1997: 70). Por lo tanto, para la conformación de esta cartografía debemos preguntarnos cómo evitar que este trabajo tienda a serializar subjetividades y cargarlas de modos artificiosos de clasificación que produzcan un aplastamiento de las singularidades de vida. Para tal tarea, seguiremos los postulados de una cartografía deseante (Perlongher, 1997). Esta no pretenderá congelar las diferencias en paradigmas identitarios estancos; por el contrario, mediante la imperiosa necesidad de habitar la fuga, devenir incapturable, encontrará puntos de pasajes y articulación, nodos desde los que se traman las representaciones y modos de visibilización de los devenires de subjetivación minoritarios. Siguiendo a Néstor Perlongher, esta cartografía no intenta fijar, clasificar los cuerpos en determinados análisis:

[S]ino que se dispone a intensificar los propios flujos de vida en los que se envuelve, creando territorios a medida que se los recorre. El mapa resultante, lejos de restringirse a las dimensiones físicas, geográficas espaciales (...) ha de ser un mapa de los efectos de superficie (1997: 65).

Por lo expuesto, esta cartografía se trama a partir de procedimientos escénicos que no constituyen una identidad única y estable, tal como se concibe la ficción de la matriz biopolítica heterocisexual. Por el contrario, se teje en aquellos modos de hacerse un cuerpo (Farneda, 2016), intersticios en el que intervienen las representaciones hegemónicas de la normatividad binaria y su deconstrucciones. Su particularidad también se puede considerar a través de los lineamientos de lo que Paul B. Preciado señaló como una cartografía queer, la cual:

[N]o propone tanto un análisis en términos de identidad, sino de producción de subjetividad, menos de posición que de movimiento, no tanto de representación 
como de performatividad, menos en términos de objeto o cuerpo que en términos de tecnologías políticas y de relacionalidad (2008: 350).

De esta manera, esta perspectiva cartográfica permite proyectar un mapa que excede el marco espacial y cronológico del Centro Cultural Rojas y, a partir flujos de subjetivación poético políticos, crea territorios existenciales. En este recorrido, retomo mi participación en el trazado de esta cartografía de las deformances en el Centro Cultural Rojas. Fue diseñada con quienes conformamos "territorios de libertad" (Cuello, 2014), cuevas o convivios (Dubatti, 2003) que operaron tal fortaleza ante el escenario político-económico de la crisis del 2001. Fue a partir de las experiencias surgidas en torno del espacio cultural auto-gestionado Giribone, el espectáculo teatral Las Noches Bizarras y las presentaciones de Klaudia con K, Julia Amore y Dominique Sanders cuando, en los bordes del circuito teatral, se instauraba la pregunta por la (in)visibilidad de las travestis en escena. En aquellas prácticas escénicas ubicadas por fuera del considerado circuito under, este recorrido se produjo a contrapelo de las historias que han obliterado devenires travestis en la escena teatral porteña.

Tradicionalmente, se puede reconocer que la figura de las drags y travestis tuvieron lugar en el ambiente de la noche en un determinado circuito de fiestas y boliches (siendo en el último tiempo las fiestas Mostrafest y Trabestia, las más reconocidas). Sin embargo, actualmente, sus presentaciones se han propagado en otros espacios culturales y artísticos. En este sentido, la cartelera porteña se inscribe en un contexto social de época ya sea visibilizando el lugar de las travestis en escena como así también la puesta en escena del travestismo como procedimiento artístico. A pesar de esta productividad, cuando esta cartografía comenzó a diseñarse, dicha emergencia no era tal y Susy Shock (hoy en día una de las activistas trans más reconocidas en Latinoamérica por su trabajo artístico), entre risas y parodias, decía que sus espectáculos pertenecían al "under del under", porque ni siquiera formaban parte del circuito cultural under. Con respecto al mencionado Centro Cultural Giribone, cabe señalar que hacia el 2006, el gobierno de la Ciudad de Buenos Aires había diseñado un mapa del circuito cultural under porteño. Una de sus zonas de mayor productividad artística se ubicaba en la movida cultural del barrio de Palermo viejo, es decir, cercano al Centro Cultural Giribone, en el barrio de la Chacarita, donde Susy Shock desarrolló sus primeros tránsitos de su actual reconocida trayectoria como artista trans sudaca, tal como ella misma se define. La desterritorialización -por unas cuadras- del Giribone de lo que el oficialismo conservador consideraba under no podía causar más que una afectación humorística por parte del colectivo Giribone. Por esta razón, se decía que dicho centro cultural estaba ubicado en el "under del under" ya que no estaba considerado entre los puntos cardinales de la cultura (oficial) under.

Frente a esta situación, se tornaba necesario dar cuenta de la participación de las travestis en la historiografía teatral de Buenos Aires. Para dicha tarea, recupero los aportes del grupo Micropolíticas de la desobediencia sexual en el arte en torno de las posibilidades de incidir en los discursos historiográficos:

Se trata, entonces, de interrumpir las ficciones de la historia (y de la historia del arte) en sus trayectorias institucionalizadas, interrogando sus silencios, fracturas, borrones y clausuras, abriendo fugas y discontinuidades críticas en los recorridos unidimensionales de sentido trazados por las narrativas hegemónicas (2014 [en línea]).

Sin duda, las tramas son más complejas y variadas y, aunque la presentación del corpus de artistas mencionado inicialmente se sujetó al tiempo lineal y cronológico de los 30 años del Centro Cultural Rojas, se puede reconocer en este recorte una heterocronía (Moxey, 2016) que se desvincula de un tiempo evolutivo. De acuerdo con Keith Moxey, dicho concepto aporta un posicionamiento político, ya que disuelve la 
linealidad del tiempo concebido de modo monocrónico dando cuenta de los flujos de poder que determinan las periodizaciones historiográficas. Por lo tanto, la cartografía teatral de las desobediencias sexo-genéricas presenta nodos, intermitencias, fugas e interrupciones en relación de las periodizaciones mayoritarias del campo teatral argentino. En estas, el corpus de artistas se sitúa insistentemente mediante operaciones de resignificación poético-políticos por el derecho al reconocimiento de la identidad de género. A través de esta cartografía se traza una lectura de prácticas escénicas que, bajo las convenciones teatrales y aún más allá de ellas, propusieron espacios heterotópicos (Foucault, 2010) desde sus dramaturgias corporales cuestionando y deformando patrones de representación heterocisnormativos: "reivindico mi derecho a ser monstruo, que otros sean lo normal", es el lema, ya colectivizado, de la poeta Susy Shock (2011: 11).

En consecuencia, tensionando modelizaciones somatopoliticas heterocisexuales y apelando a la deconstrucción de las ficciones reguladoras de las tecnologías corporales, el corpus de artistas que diseña esta cartografía teatral distorsionó los constructos corporales hegemónicos con prácticas escénicas que aquí, recuperando un término acuñado por Naty Menstrual (en diálogo personal, 2013), denominamos: deformances. A continuación, se fundamenta dicha noción bajo la cual se agrupa el corpus de artistas mencionado (Batato Barea, Fernando Noy, Klaudia con K, Mosquito Sancineto, Susy Shock, Dominique Sanders, Julia Lagos, Malva Solís, Naty Menstrual, Camila Sosa Villada, Julia Amore y Lukas Avendaño).

\section{(In)definiciones de las deformances}

(...) se pueden mirar las realidades desde otro punto de vista, afirmar que quien es observado por el analista posee también una mirada y un discurso. Y que esta mirada, esta palabra, juzgan a quien se crea el único facultado para mirar y hablar

(Eribon, 2004: 286)

El 28 de noviembre de 2007, en el Centro Cultural Rojas, se realizó el lanzamiento del primer número de El Teje. Para el evento, se presentaron distintas performances escénicas en las cuales participaron Naty Menstrual, Julia Amore, Fernando Noy, Dominique Sanders y Julia Lagos. En un contexto de época en el que lo queer se imponía como categoría para considerar las desobediencias sexo-genéricas, en aquella oportunidad, les comenté a algunos/as de los/as performers acerca de la posibilidad de adscribir sus trabajos bajo dicha categoría. Frente al desconocimiento del término y el ímpetu imperialista que este denotaba, la repudiaron, al tiempo que reivindicaron su condición travesti, "a lo sumo trans".

Considerando dicha resistencia y en la reflexión que las distintas presentaciones de lanzamiento de El Teje. Primerperiódico travestiy las prácticas performáticas sucedidas en Giribone (espacio cultural en el que Susy Shock era la madame del espacio y vedette de Las Noches Bizarras) comenzaba a proyectarse una genealogía desobediente entre las prácticas escénicas de la década del ochenta (de Batato Barea) y la recuperación de su figura en el contexto político de los primeros años del nuevo milenio. Años después, en diálogo con Naty Menstrual acerca de sus performances en las presentaciones de lanzamiento de El Teje, me manifestó lo siguiente:

No hice performance en el Rojas. Presenté mi libro. No hago performance en el Rojas. No hago performance iOdio la palabra performance! Hice una puesta en escena. Hago un show de lectura expresiva. Me expreso mediante mi lectura. A lo sumo ¿Sabes lo que hago? Hago deformances" (en diálogo personal, Bar MU, 2013) 
De esta manera, Naty Menstrual se desidentificaba de conceptos del campo del arte, al tiempo que, interrumpía las lógicas del academicismo que intenta catalogar prácticas que no se sujetan a etiquetas generalizantes. Por lo tanto, en el transcurso del diseño de esta cartografía teatral, una y otra vez, las categorías que en el campo artístico circulaban y con las cuales se consideraban las prácticas escénicas, sobre las cuales me interesa reflexionar, fueron cuestionadas en los diálogos mantenidos con quienes conformaban el corpus de artistas. Por ello, retomo el término propuesto por la artista ya que imprime una potencia crítica para abordar las intervenciones escénicas en las que el travestismo cuestionó los regímenes de visibilidad. Asimismo, su irónica hilaridad hace un llamamiento a las marcas del pensamiento heterosexual. De acuerdo con Monique Wittig: "Estos discursos de heterosexualidad nos oprimen en la medida en que nos niegan toda posibilidad de hablar si no es en sus propios términos y todo aquellos que los pone en cuestión es enseguida considerado como 'primario'" (2006 [1992]: 49). Para desarticular estas lógicas, si teatro en su etimología griega significa lugar para ver, me pregunto qué mirada cuestionaban y/o demandaban estas prácticas escénicas.

En consecuencia, acerca del teatro de la mirada allí acontecido, se debe advertir que, en este estudio, no interesa concebir el travestismo en su definición tradicional, es decir, como "el cambio de ropa del sexo contrario", ya que no se trata de abordar solamente el cambio de atavíos en prácticas escénicas. A partir de esta perspectiva de lectura, la performatividad del término acunado por Naty Menstrual desplaza la neutralidad de la categoría de performance y le otorga un giro semántico al acto de deformar. De este modo, el neologismo oficia como aquel dispositivo que recupera la injuria para resignificar aquellos procesos de subjetivación que no se ciñen al sistema de modelizaciones corporales socio-culturales hegemónicos. ${ }^{8}$ Si bien la carga política del término instituye una lectura que contiene la transgresión de las categorías de género y su deconstrucción esencialista, la reflexión que se despliega no pretende comprobar su efecto solamente en estos términos. De acuerdo con dicha teoría de la performatividad queer, Kosofsky advierte:

[C]iertos académicos están tratando de darle a la performatividad, tal y como ellos creen que la comprenden a partir del trabajo de Judith Butler y otros textos relacionados: forzando los ojos para mirar si algunos performances particulares (por ejemplo el drag) son realmente una parodia o subversión (de, por ejemplo, el esencialismo de género) o sólo mantienen el statu quo. En el fondo la conclusión es casi siempre la misma: parcialmente subversivo, parcialmente hegemónico. Veo esto como una domesticación tristemente prematura de una herramienta conceptual cuyos poderes justo hasta ahora hemos empezado vagamente a explorar (1999: 212).

Por lo tanto, de acuerdo con los postulados de Teresa De Lauretis:

En la última década, más o menos, la semiótica ha sufrido un cambio en su engranaje teórico: un cambio que la ha alejado de la clasificación de los sistemas de signos -sus unidades básicas, sus niveles de organización estructural-y la ha llevado a la exploración de los modos de producción de signos y significados, a las formas en que se usan, se transforman o se violan los códigos y los sistemas en la actividad social. Mientras que antes se ponía el énfasis en el estudio de los sistemas de signos (el lenguaje, la literatura, el cine, la arquitectura, la música, etc.), concebidos como mecanismos que generan mensajes, lo que se estudia ahora es la función que se lleva a cabo a partir de ellos. Es esta función o actividad lo que constituye y/o transforma los códigos, al mismo tiempo que constituye y transforma a los individuos que usan esos códigos, que llevan a cabo esa actividad; los individuos que son, por tanto, el sujeto de la semiosis (1992: 265 [el subrayado me pertenece]).
8. Para una mayor comprensión de la apropiación de la injuria, véase el capítulo: "Acerca del término queer" en Cuerpos que importan de Judith Butler (2008). 
Por lo expuesto, si bien a través de la teoría de la performatividad de género se pueden considerar estos acontecimientos como falla en la iteración de los actos a través de los que nos volvemos sujetos inteligibles, se trata de considerar que estos acontecimientos escénicos travisteriles devienen "estrategias de teatralización política a través de las que el cuerpo excluido por el régimen disciplinario y su estructura de lo sensible se hace visible en el espacio público", tal como concibe Preciado (2011) el campceptualismo de la Ocaña (artista andaluz de la movida madrileña). De esta manera, los dispositivos poéticos escénicos -elementos de género o de interacción social, en términos de Halperin (2016)- que intervienen en el devenir travesti sedimentan determinadas figuraciones y corporalidades, al tiempo que deconstruyen dichas modelizaciones mediante prácticas escénicas performativas las cuales, siguiendo a Preciado (2011), se inscriben en la estratificación biopolítica de la modernidad generando procesos de subjetivación contraproductivos al orden mayoritario. De acuerdo con Preciado (2011), la estratificación biopolitica de la modernidad se conforma también por otros sectores sociales desplazados, entre ellos: judíos, homosexuales, prostitutas y vagabundos, pero también teatristas errantes del campo teatral legitimado y otras disciplinas artísticas de mayor jerarquización social, entre ellas, las artes plásticas.

En este sentido, así como entre género y diferencia sexual, el lazo que unía el binomio debía ser desatado y deconstruido para complejizar el análisis a través de la comprensión de las tecnologías de subjetivación biopoliticas que dan cuenta del "conjunto de efectos producidos en los cuerpos, los comportamientos y las relaciones sociales" (De Lauretis, 1996: 8), interesa aquí considerar las deformances escénicas como otras tramas mediante las cuales los devenires travestis se constituyen, pero no como identidad univoca y estable que imita una figura previa (la femenina), sino como aquella potencia desestabilizadora de las formas de representación de las identidades sociales normativas.

Asimismo, a pesar de la potencia política del término, dado que toda categoría analítica instaura una sospecha crítica, debemos preguntar si acaso un acontecimiento poético performático puede instituir tal fuerza política para subvertir y transgredir constructos sociales cuya carga ideológica androcéntrica se encuentra arraigada en el imaginario heterosexual. En palabras de Eve Kosofsky Sedgwick: "No cabe esperar un potencial de transformación en la exhibición teatral de una ignorancia ya institucionalizada" (1998: 104). Lo particular de este corpus de artistas es que conforman una trama micropolítica, una cartografía que socava el régimen heterocisexual de modo poético y colectivo. También resulta oportuno considerar si, por fuera de esta cartografía, las puestas de quienes conforman dicho corpus se inscriben en el continúo descentramiento de los constructos identitarios de género. Dado que el género es transversal en todo ámbito y disciplina (tanto para mujeres y hombres, como para toda adscripción sexo genérica disidente), la labor artística de quienes conforman el corpus excede su posicionamiento identitario en tanto producción política de la subjetividad. Por lo cual, sospechamos de la funcionalidad para aplicar la perspectiva de las deformances en todas las intervenciones escénicas realizadas por los/as artistas del corpus o de todas las personas trans/travestis que integran la cartelera teatral porteña. Acerca de los procesos de identificación Michel Foucault indica:

[S]i la identidad se convierte en el problema capital de la vida sexual, si la gente cree que ha de descubrir su propia identidad y que esta identidad ha de erigirse en norma, principio y pauta de existencia; si la pregunta que se formulan de continuo es: “¿Actúo de acuerdo con mi identidad?”, entonces retrocederán a una especie de ética semejante a la de la virilidad heterosexual tradicional.

Si hemos de pronunciarnos respecto a la cuestión de la identidad, hemos de partir de nuestra condición de seres únicos. Las relaciones que debemos trabar con nosotros mismos no son de identidad, sino más bien de diferenciación, crea- 
ción e innovación. Es un fastidio ser siempre el mismo. No debemos descartar la identidad si a través de ella obtenemos placer, pero nunca debemos exigir esa identidad en norma ética universal (1984, [en línea]).

En este sentido, el posicionamiento identitario trans/travestis de la presente cartografía interesa atender siempre y cuando los/as performer se inscriben desde dicho locus de enunciación política. Sin embargo, cuando sus trabajos no refieren o no se configuran en una trama poético política sexo-genérica desobediente, sospechamos de la estrategia de enunciación de las deformances, ya que, si bien el uso discursivo universalizante puede -paradójicamente- instituir una forma de reivindicación performativa, también constituye un dispositivo neutralizador (e integracionista) de las diferencias. ${ }^{9}$ Asimismo, considerar que, por devenir travesti, toda la producción de los/ as artistas aquí abordados/as puede enmarcarse en el dispositivo de las deformances conllevaría un gesto que avala aquellas supuestas escrituras femeninas, arte trans/travesti o teatro queer. Por lo tanto, aquí nos centramos en aquellas producciones escénicas que, de modo insurgente, posicionaron sus historias de vida contraculturalmente ante la normalización biopolitica de la cis heterosexualidad. En consecuencia, para la cartografía teatral desobediente se debe mencionar que la experiencia actúa como nodo semiótico (de resistencia política) desde la cual se desarrollan y sedimentan las prácticas performáticas de los devenires de subjetivación minoritarios.

Siguiendo a Monique Wittig, este tipo de perspectivas de lecturas supone el riesgo de hacer prevalecer el aspecto social sobre el artístico y "cuando esto ocurre, el texto deja de funcionar en el nivel literario [artístico], ya no es considerado en relación con otros textos equivalentes" (2006: 88). Retomando estas advertencias, para abordar las formas de significación en que las tramas vitales se (re)presentan, se establecen cruces analíticos e historiográficos entre las técnicas y poéticas teatrales desde las cuales se inscribieron dichas trayectorias como instancia de reprogramación del género (Preciado, 2008a). Los talleres drag king son considerados por Paul B. Preciado como un dispositivo mediante el cual es posible, progresivamente, reprogramar el ordenamiento biopolitico de los géneros: "Se trata de la puesta en marcha de un proceso a través del cual un conjunto de tecnologías de producción de identidad de género se activan o desactivan" (2008a: 266). Anclarse en estas prácticas no resulta una tarea sencilla y sin contradicciones, por el contrario: "La batalla es dura porque debe lucharse en dos frentes: en el nivel formal con las cuestiones que se debaten en ese momento de la historia literaria [teatral], y en el nivel conceptual contra los presupuestos a priori del pensamiento heterosexual" (Wittig, 2006:91). En consecuencia, las ausencias del travestismo escénico o las travestis en la literatura teatral no responde tanto a su inexistencia (aunque participaron escasamente en prácticas escénicas reconocidas), sino a un posicionamiento ideológico androcéntrico que marginó sus intervenciones por falta de un aporte poético - artístico.

De acuerdo con la cartografía teatral de las desobediencias sexo-genéricas, aunque en la genealogía performática del travestismo escénico existen modos de enunciación y contagios entre las poéticas y sus procedimientos, estos no resultan instancias prefijadas. Si bien predomina la parodia y el humor, cada artista performa su propio devenir a través de distintas estrategias escénicas. Mientras que las prácticas del carnaval fueron aquellos espacios de agenciamiento y visibilidad de las travestis y maricas de antaño, estas se contaminaron con la poesía performática (Garbatzky, 2013) en la década del ochenta, para, luego, inscribirse en la performatividad irreverente del Match de improvisación como aquella instancia en la que se improvisa el género. De acuerdo con el corpus de artistas, ya en el nuevo milenio, las deformances escénicas devienen singulares, sin posibilidad de responder a una poética específica. Entre el biodrama y las varietés, los procedimientos grotescos y el humor político, el devenir travesti toma cuerpo en escena. A pesar de que distintos estudios consideran esta emergencia
9. Acerca de la paradoja de conceptos universales, véase Deshacer el género de Judith Butler (2006). 
(desde la apertura democrática en adelante) en tanto nuevas corporalidades, creemos oportuno señalar la implicancia del movimiento social de las minorías sexuales para dar cuenta del activismo trans en escena (Lozano, 2015), inclusive más allá del contexto político actual. De este modo, aun sin un movimiento social que escolte estas prácticas performáticas, las travestis han transitado escenarios y prácticas festivas del carnaval exhibiendo sus cuerpos como una escenificación política cuando los edictos policiales tenían plena vigencia. En estas prácticas se "producen lazos comunitarios que sostienen a sus miembros y mediante los cuales se posibilita el reconocimiento, además de rechazar la violencia, el racismo, la homofobia y la transfobia", tal como sugiere Judith Butler (2006: 305) en torno a las performances de las drag queens. Por su parte, Marlene Wayar indica que a través de los espectáculos "se defiende la alegría y el humor a pesar de la violencia del contexto" (en Tauil, 2010 [en línea]). Por lo tanto, no resulta casual considerar el carácter popular de las deformances en las que se inscriben los devenires travestis como discursos e intersticios, desde los cuales se desajustan los códigos sociales mediante la recuperación del cuerpo, el placer, el exceso y la comicidad. Particularmente, interesa concebir estas prácticas en tanto carnavalización (Perlongher, 1997), es decir, subjetivaciones que se constituyen por fuera del límite temporal del carnaval. Bajo esta lógica carnavalesca que se extiende hacia los tránsitos vitales, se alteran los códigos sociales; se invierte lo alto y lo bajo; lo trágico y lo cómico diluyen sus fronteras, tal como Halperin (2016 [2014]) señala acerca de las prácticas de las subjetividades queer. De esta manera, las deformances del corpus de artistas que participó en el Centro Cultural Rojas alteraron la frontera de lo visible en la vida pública y las prácticas escénicas configuran formas colectivas de subjetivación y, de acuerdo con sus propios deseos de ser, tensionaron la ficción heterocisexual.

Asimismo, las deformances se pueden considerar a partir de la conceptualización de la desidentificación de Estaban Muñoz (2011 [1999]) quien, a través del paradigma del lingüista Michel Pecheux, establece tres modos de prácticas ideológicas mediante las que nos constituimos. ${ }^{10}$ La primera es la identificación en la cual el buen sujeto no establece reticencias a las formas discursivas e ideológicas dominantes, es decir, las formaciones se asimilan a un orden mayoritario. La segunda consiste en la contraidentificación en la que los sujetos se resisten, rechazan y se rebelan a los símbolos que ofrece la ideología y los subvierten. Por último, la estrategia de la desidentificación no radica en asimilar la ideología ni rechazarla estrictamente, sino que opera desde dentro de ella y contra ella misma. Estas prácticas resultan:

[E]strategias de supervivencia que pone en práctica el sujeto que pertenece a una minoría con el fin de negociar con una esfera pública fóbica mayoritaria que todo el tiempo acalla o castiga la existencia de sujetos que no se ajustan al espectro de la ciudadanía normativa (Muñoz, 2011: 557).

A su vez, el mismo Muñoz retoma las paradojas del mecanismo del poder desarrolladas por Michel Foucault, quien complejiza la relación entre los discursos dominantes y aquellos dominados para señalar que ni unos están sometidos para siempre ni otros inciden contra él continuamente; por el contrario, las relaciones de poder que instauran los discursos no solo reprimen, sino que también producen estrategias de resistencia. Por lo tanto, "El discurso transporta y produce el poder; lo refuerza, pero también lo mina, lo expone, lo torna frágil y permite desbaratarlo" (Foucault en Muñoz, 2011: 577). Por su parte, Muñoz indica que de lo que se trata es de problematizar la identidad y la identificación, los modos de alterar y reestructurar los patrones de los medios dominantes:

La desidentificación tiene que ver con reciclar y repensar un significado codificado. El proceso de desidentificación revuelve y reconstruye el mensaje codificado de
10. Muñoz especifica que Michel Pecheux se basa en "La ideología y aparatos ideológicos del Estado" de Althusser para pensar la formación del sujeto. 
un texto cultural de manera que tanto expone las maquinaciones universalizadoras y excluyentes del mensaje codificado como reacomoda los circuitos de sus mecanismos para que contemplen, incluyan y fortalezcan las identidades e identificaciones de las minorías. Así, la desidentificación es un paso más que la mera resquebrajadura del código de la mayoría; procede a emplear este código como materia prima para representar una política o una postura, privada de su fuerza, que la cultura dominante convirtió en algo impensable (2011: 595).

A través de estas consideraciones se puede señalar que el dispositivo conceptual de las deformances también opera a través de esta lógica cultural mayoritaria. Esta referencialidad es inminente en la medida en que, como sostiene Foucault, "La resistencia se apoya, en realidad, en la situación contra la cual combate" (1984 [en línea]). En este mismo sentido, proyectamos las consideraciones de las deformances en tanto tensionan procedimientos escénicos, códigos y convenciones del régimen heteronormativo que intenta desestabilizar. Dado que dicho régimen es una copia sin original (tal como señala Butler en relación al género), su propio proceso de performatividad también varía. Además, si bien el régimen heterocisexual será el único punto de apoyo en común entre las diferentes deformances, la singularidad de las producciones escénicas resultarán propias de sus contextos de producción de sentido y las operaciones de agenciamientos micropoliticos de sus artistas.

Por lo dicho, las deformances se alzan como una categoría abierta y contingente que tensiona el campo cultural con el que interactúan sin remitir de modo alguno a un marco preconstituido de procedimientos artísticos o modelizaciones corporales. Además, si bien aquí se aborda la noción desde una perspectiva de géneros, interesa ampliar el dispositivo de reflexión para toda propuesta estético-artística que desande modelos corporales hegemónicos. De esta manera, de acuerdo con las reflexiones de Judith Butler (2008) acerca del término queer, resulta necesario dejar planteada la apertura semántica de toda categoría.

En consecuencia, las deformances instituyen un paraguas conceptual bajo el cual pueden inscribirse experiencias diferenciales, como por ejemplo, el trabajo de la artista visual estadounidense, Liz Gibson (www.deformanceart.com) cuya propia nominación deformances art alude directamente al término aquí propuesto. Por otro lado, la familiaridad del término también se puede reconocer en instancias como la Bienal de Performance: Deformer curada por Gonzalo Rabanal en Santiago de Chile (la cual se realiza desde 2002 hasta la fecha) o el seminario "Deformances" dictado por el politólogo y director de escena venezolano, Giuseppe Grasso, quien propuso un estudio anatómico de las manifestaciones artísticas del siglo XX y una serie de ejercicios físicos en el marco del Encuentro Internacional de Teatro Mérida (Venezuela) realizado del 11 al 16 de abril de 2016. Por lo tanto, consideramos las deformances como un dispositivo de enunciación escénica -en esta oportunidad-y no como una disciplina, poética o estilo artístico. Una categoría que demanda una reflexión continúa para sostener la disputa conceptual. ${ }^{11}$ Siguiendo a Judith Butler, las categorías identitarias operan como error necesario, es decir, resultan una instancia de filiación conceptual pero se debe "ratificar su contingencia" (2008: 323) como una estrategia político-discursiva mediante la cual señalar la fuerza performativa de la materialidad de los cuerpos para intervenir en la productivización normativa. A través de ellas, y en ellas, las corporalidades desterritorializan las tecnologías genéricas instauradas por el régimen heterosexual y producen procesos de desidentificaciones mediante las cuales los cuerpos desdibujan las fronteras de inteligibilidad. En igual sentido se propone el término de las deformances, en tanto este conlleva una amplitud futura para que en el quepan significados aun no previstos, pero que, a través de ellos, se puedan desestabilizar marcos de legibilidad hegemónicos.
11. Tal contingencia conceptual propone Judith Butler en relación al término queer en Cuerpos que importan (2008). 


\section{Consideraciones finales}

De acuerdo con el recorrido propuesto, la figura Batato Barea se inscribió en tanto espectro mediante el cual esbozar un recorrido de lectura del Centro Cultural Rojas en sus 30 años de actividad (1984-2014). En la década del ochenta, la dramaturgia corporal del primer claun-travesti-literario provocó una serie de discursos críticos y escénicos insurgentes del sistema sexo-género, los cuales resonaron en la década del noventa y, en el nuevo milenio, en el activismo trans nucleado en el Área de Tecnologías de Género y el proyecto editorial El Teje. Primer periódico travesti latinoamericano. Considerando que, el colectivo $T$ fue discriminado sistemáticamente de distintos ámbitos de la sociedad y, en especial, de las instituciones educativas (el Rojas depende de la Universidad de Buenos Aires), interesó indagar acerca del perfil institucional del espacio cultural para dar cuenta de cómo fue posible aquel tránsito desobediente capaz de configurar una cartografía teatral.

En esta tarea, se sugirió que esto fue posible porque el Rojas se fundó en 1984 en el marco de los presupuestos básicos del Área de Extensión Universitaria, espacio institucional del cual dependió hasta el año 2002. En este sentido, las actividades debían integrar el contorno social a la universidad. Sin embargo, los testimonios ofrecidos por quienes trabajaron en los primeros años de la gestión pusieron de manifiesto que la impronta cultural alternativa, dislocada (Rosa, 2008), desprejuiciada (Lebenglik, 2009), innovadora (Vázquez, 2009) y hereje (Cerviño, 2012) propia del Rojas, no constituyó un programa a cumplir por las distintas gestiones, sino que fue impulsada, de manera cómplice, como una acto de resistencia política a partir de distintas plataformas que, trabajando de modo colaborativo, propiciaron pasajes insurgentes, entre ellos, el de los devenires travestis en la escena. Asimismo, la profusa labor escénica de Barea y las tramas que fue estableciendo hicieron posible que un corpus de artistas se inscriba bajo su manto de rebeldía cuestionadora de las estancas y binarias categorías de género.

Resulta necesario destacar que, si bien las prácticas escénicas del corpus mencionado sucedieron de manera dispersa, perdidas en la cuantiosa actividad del Centro Cultural Rojas fueron destellos de una constelación mayor. Aquí, mediante una mirada oblicua y descentrada, a través del dispositivo conceptual de las deformances se propuso aunar un recorrido cartográfico a contrapelo de relatos historiográficos que obliteraron por inmoral, insignificantes o carentes de calidad artística prácticas escénicas las cuales, haciendo estallar las normas genéricas, deforman la materialidad del cuerpo y cuestionan el reparto de lo sensible (Rancière, 2011). De esta manera, lo particular de esta maquinaria conceptual contra-productiva radica en considerar la matriz política mediante la cual se cuestionaron los regímenes de visualidad de las corporalidades hegemónicas. Por todo lo expuesto, no es el objetivo de este recorrido establecer nuevos paradigmas identitarios; por el contrario, el trazado de esta cartografía teatral sexo-genérica desobediente, lejos de definir rasgos comunes, posibilita que cada artista se inscriba mediante procedimientos escénicos, técnicas de actuación y modalidades de intervención diferenciales. En estas derivas, sus tránsitos vitales liminales a sus prácticas artísticas crearon territorios de libertad (Cuello, 2014) como gesto de reafirmación subjetiva.

En próximos trabajos, continuando con las líneas investigación aquí planteadas, se aspira profundizar el estudio mediante la descripción analítica de los distintos acontecimientos escénicos del corpus de artistas que dislocaron el sistema [sic] de representación heterosexual en el Centro Cultural Rojas entre 1984-2014. En tales abordajes las resonancias de la -ya clásica- pregunta: “¿Por qué no han existido grandes artistas mujeres en la historia del arte?" de Linda Nochlin (1971), se actualiza críticamente: ¿Por qué no existieron travestis en la historia del teatro argentino? ${ }^{12}$ Siguiendo este interrogante, nuestras próximas indagaciones sumarán nuevas reflexiones en torno de la compleja relación que instauró el hecho artístico (específicamente teatral) con su referente cultural en general, y político, en particular.
12. La pregunta de Linda Nochlin fue el título de su artículo publicado en Art News, no 69, pp. 22-39, en enero de 1971: “¿Why have there been no great women artists?". 


\section{Dibliografía}

» Butler, J. (2006 [2004]). Deshacer el género. Barcelona: Paidós.

"Butler, J. (2008 [2002]). Cuerpos que importan. Sobre los límites materiales y discursivos del "sexo". Buenos Aires: Paidós.

» Castro, O. y Tacani, G. (2009). “Desde un edificio olvidado”. En Calzón Flores (comp.), 25 Años del Rojas. (pp. 77). Buenos Aires: Libros del Rojas, UBA.

"Cerviño, M. (2012). "La herejía del Rojas. Ethos disidentes e innovación artística en Buenos Aires, en la post-dictadura". En Wortman, A. (ed.), Mi Buenos Aires Querido. Entre la democratización cultural y la desigualdad educativa. (pp. 129147). Buenos Aires: Prometeo.

»Cuello, N. (2014, 7 de agosto). "Metodologías de la decepción: Estrategias críticas para la investigación en prácticas artísticas contemporáneas y políticas sexuales". Ponencia presentada en: I Jornadas de Investigación sobre Políticas Visuales de los Afectos, organizadas por el Grupo de Trabajo Políticas Visuales de los Afectos. LabIAL. Facultad de Bellas Artes, UNLP.

"Cuello, N. y Lemus, F. (2016). “'De cómo ser una verdadera loca’. Grupo de Acción Gay y la revista Sodoma como geografías ficcionales de la utopía marica”. Revista Badebec. Revista del Centro de Teoría y Crítica Literaria, 6 (11), [en línea]. Consultado el 03 de noviembre de 2018 en: https://revista.badebec.org/index. php/badebec/article/view/222.

» De Lauretis, T. (1992[1984]). Alicia ya no. Feminismo, semiótica, cine. Madrid: Ediciones Cátedra. Universitat de Valéncia. Instituto de la Mujer.

»De Lauretis, T. (1996 [1989]). “La tecnología del género”. Mona - Revista del Área Interdisciplinaria de Estudios de la Mujer, (2), 6-34.

»Deleuze, G. y Guattari, F. (2002 [1988]). Mil mesetas. Capitalismo y esquizofrenia. Valencia: Pre-textos.

»Departamento de Extensión Universitaria (1957). 1er año de Extensión Universitaria. Buenos Aires: UBA.

"Dillón, M. (2006, 18 de agosto). “Poemas cosidos en el borde”. En Diario Pág. 12. Suplemento Las 12, [en línea]. Consultado el 2 de noviembre de 2018 en: https:// www.pagina12.com.ar/diario/suplementos/las12/26-2834-2006-08-18.html

»Dubatti, J. (2003). El convivio teatral. Teoría y práctica del teatro comparado. Buenos Aires: Atuel.

»Dubatti, J. (2008). Cartografía teatral. Introducción al teatro comparado. Buenos Aires: Atuel.

"Dubatti, J. (2009). "El Rojas, espacio abierto a las nuevas tendencias en teatro y danza”. En Calzón Flores, N. (comp.), 25 Años del Rojas. (pp. 258-267). Buenos Aires: Libros del Rojas, UBA.

"Eribon, D. (2004 [2001]). Una moral de lo minoritario. Variaciones sobre Jean Genet. Barcelona: Anagrama.

» Farneda, P. (2016) "Prácticas de sí: subjetividades contemporáneas en las expresiones artísticas trans actuales en Buenos Aires". Tesis doctoral. Facultad de Filosofía y Letras, Universidad de Buenos Aires. 
» Foucault, M. (2010 [1966]). El cuerpo utópico. Buenos Aires: Nueva Visión.

" Foucault, M.. (1984 [en línea]). “Sexo, poder e identidad”. Entrevista dirigida por B. Gallagher y A. Wilson en Toronto, junio de 1982. Traducción del inglés de Luis Cayo Pérez Bueno. The advócate, (400), [en línea]. Consultado el 5 de noviembre de 2018 en: https://artilleriainmanente.noblogs.org/post/2016/04/21/ michel-foucault-sexo-poder-y-la-politica-de-la-identidad-entrevista/

»Garbatzky, I. (2013). Los 80 recién vivos. Poesía y performances en el Rio de La Plata. Rosario: Viterbo.

»Gutiérrez, M. L. (2018). Imágenes de lo posible. Intervenciones y visibilidades feministas en las prácticas artísticas en la Argentina (1985 - 2013). Tesis doctoral. Facultad de Sociales, Universidad de Buenos Aires.

» Halperin, D. (2016 [2014]). Como ser gay. Valencia: Tirant humanidades. Pensamiento político contemporáneo.

» Hojman, E. (1989, 9 de septiembre). “Simplemente un marginal”. En Sur, p. 25.

" Jiménez, P. (2009, 4 de septiembre). “Tinta Rojas”. En Página 12. Suplemento Las 12, [en línea]. Consultado el 14 de noviembre de 2018 en: https://www. pagina12.com.ar/diario/suplementos/las12/13-5151-2009-09-06.html

» Kamenszain, T. (2009). “Una relación viva con la cultura”. En Calzón Flores, N. (comp.), 25 Años del Rojas. (pp. 19). Buenos Aires: Libros del Rojas, UBA.

» Kosofsky Sedgwick, E. (1998 [1990]). Epistemología del armario. Barcelona: Ediciones de la tempestad.

» Kosofsky Sedgwick, E. (1999, 10 de abril). "Performatividad queer. The art of the novel de Henry James”. Nómadas (10), 198-214.

»Lebenglik, F. (2009). “Una usina cultural”. En Calzón Flores, N. (comp.), 25 Años del Rojas. (pp. 187-188). Buenos Aires: Libros del Rojas, UBA.

"Leonardi, Y. y Verzero, L. (2008). "La dialéctica espacio-comunidad en las experiencias teatrales de los primeros años 70 ". telondefondo. Revista de Teoría y Critica Teatral, 4 (8), [en línea]. Consultado el 03 de noviembre de 2018 en: http://www.telondefondo.org/numeros-anteriores/numero8/articulo/179/ladialectica-espacio-comunidad-en-las-experiencias-teatrales-de-los-primerosanios-\%EF\%BF\%BD7o.html

» Link, D. (2009). “Galaxia Rojas”. En Calzón Flores, N. (comp.), 25 Años del Rojas. (pp. 254). Buenos Aires: Libros del Rojas, UBA.

»Longoni, A. (ed.) (2011). El deseo nace del derrumbe. Roberto Jacoby. Acciones, conceptos, escritos. Barcelona: La Central, Adriana Hidalgo Editora, Museo Nacional Centro de Arte Reina Sofía, Red Conceptualismos del Sur.

"Lucena, D. (2013). "Guaridas under para Dionisio". Arte y Sociedad, (4), [en línea]. Consultado el 7 de noviembre de 2018 en: http://asri.eumed.net/4/guaridas-underground-dionisios.pdf

»Lucero, Z. (2007, 29 de noviembre). "Entrevista a Marlene Wayar, directora de El Teje”. En Argentina Idymedia, [en línea]. Consultado el 21 de marzo de 2019. En: http://archivo.argentina.indymedia.org/print.php?id=568312\&comments=yes

» Micropolíticas de la desobediencia sexual en el arte (Davis, F., dir.) (2016). “Artes y sexo política. Contra escrituras del arte político y latinoamericano desde el culo del mundo". Revista Fe de erratas, (1), 106-112.

»Micropolíticas de la desobediencia sexual en el arte (Davis, F., dir.) (2014, 18 de 
Noviembre). “Poéticas de la falla, archivos dañados y contraescrituras sexopolíticas de la historia del arte". Coloquio Internacional "De una raza sospechosa: Arte, archivo, memorias, sexualidades", organizado por la Coordinadora Universitaria de Disidencia Sexual en el Archivo Nacional de Chile.

"Molina, D. (2009, 19 de septiembre). "El Rojas en primera persona”. En La Nación, [en línea]. Consultado el 10 de noviembre de 2018 en: https://www. lanacion.com.ar/1174721-el-rojas-en-primera-persona.

»Molina, D. (2009a). “Aniversario del Rojas”. En Calzón Flores, N. (comp.), 25 Años del Rojas. (pp. 249-253). Buenos Aires: Libros del Rojas, UBA.

» Moreno, M. (2003, 28 de diciembre). "La generación del ochenta”. En Diario Página 12. Suplemento Radar, [en línea]. Consultado el 17 de noviembre de 2018. En: https://www.pagina12.com.ar/diario/suplementos/radar/9-1149-2003-12-28. html

» Moxey, K. (2016). El tiempo de lo visual. La imagen en la historia. Vitoria GasteizBuenos Aires: San Soleil Ediciones.

» Muñoz, J. E. (2011). “Introducción a la teoría de la desidentificación”. En: Taylor, D. y Fuentes, M. Estudios avanzados de Performance. (pp. 549-603). México: Fondo de Cultura Económica.

»Naty Menstrual (2013, marzo). “Entrevista realizada por Mina Bevacqua: ‘¿sabes lo que hago? ¡Hago deformances!”. Ciudad Autónoma de Buenos Aires. Sin publicar.

» Nochlin, L. (2007 [1971]). “¿Por qué no existen grandes artistas mujeres?”. En Cordero, K. y Saénz, I. (comp.), Crítica feminista en la teoría e historia del arte. (pp. 17-43). México: Universidad Iberoamericana y Biblioteca Francisco Xavier Clavigero.

»Pacheco, C. (1992, 3 de junio). "El Centro Ricardo Rojas de la UBA es definido como “un laboratorio de política cultural”". En La Maga, p. 2.

»Perlongher, N. (1997). Prosa plebeya. Ensayos 1980-1992. Buenos Aires: Colihue

» Pinta, M. F. (2013). Teatro expandido en el Di Tella. Buenos Aires: Biblos.

»Preciado, P. B. (2003). "Multitudes queer. Notas para una política de los 'anormales"”. Revista Multitudes, (12), [en línea]. Consultado el 9 de noviembre de 2018. En: http://www.multitudes.net/?id_rubrique $=141$

»Preciado, P. B. (2008a). Testo yonky. Madrid: Espasa.

»Preciado, P. B. (2009). "La invención del género, o el tecnocordero que devora a los lobos”. A.A.V.V, Biopolítica. Conversaciones feministas. (pp. 15-38). Buenos Aires: Ají de Pollo.

"Preciado, P. B. (2011). “La Ocaña que merecemos. Camceptualismo. Subalternidad y políticas performativas”. En Romero, P., Ocaña, 1973-1983: Acciones, Actuaciones, Activismo. (pp. 72-169). Barcelona: Polígrafa.

»Risler, J. y Ares, P. (2013). Manual de mapeo colectivo: recursos cartográficos críticos para procesos territoriales de la creación colaborativa. Buenos Aires: Tinta Limón.

"Rosa, M. L. (2008, diciembre). “Un territorio dislocado”. Ramona, (87), 31-34.

"S/d. (1989, 23 de diciembre). "Niní Marshall: ciudadana ilustre de Buenos Aires". Carpeta de prensa 1989. Museo Casa Batato Barea.

"S/d. (1991). “Un travesti disfrazado de María Julia”. En Revista Flash. Carpeta de 
prensa 1991. Museo Casa Batato Barea.

»Sarlo, B. (2009). “La movida del Rojas”. En Calzón Flores, N. (comp.), 25 Años del Rojas. (pp. 139-140). Buenos Aires: Libros del Rojas, UBA.

» Schwarzberg, L. (2009b). “Un perfil distinto”. En Calzón Flores, N. (comp.), 25 Años del Rojas. (p. 24). Buenos Aires: Libros del Rojas, UBA.

» Schwarzberg, L. (2009). “Desembarcar en una parte del Estado”. En Calzón Flores, N. (comp.), 25 Años del Rojas. (p. 12). Buenos Aires: Libros del Rojas, UBA.

» Schwarzberg, L. (2009a). “Tamara”. En Calzón Flores, N. (comp.), 25 Años del Rojas (p. 18). Buenos Aires: Libros del Rojas, UBA.

»Soto, I. (2017, 23 de junio). “Tres veces Copi en el Teatro Cervantes”. En Clarín. Revista Ñ, [en línea]. Consultado el 8 de noviembre de 2018. En: https://www. clarin.com/revista-enie/escenarios/veces-copi-teatro-cervantes_o_ByUuRnYX-.html

»Susy Shock, (2011). Poemario transpirado. Buenos Aires: Nuevos Tiempos.

" Tauil, J. (2010, 2 de abril) “Espejito, espejito”. En Página 12. Suplemento Soy. 2 (86), p. 9.

»Ugarte, M. (2014). Antes del Rojas ¿Qué? Una historia del Teatro de la Universidad de Buenos Aires (1974-1983). Buenos Aires: ed. del autor.

》Urdapilleta, A. (2008). Vagones transportan humo. Buenos Aires: Hidalgo.

»Vázquez, C. (2009). “Referente para la innovación”. En Calzón Flores, N. (comp.), 25 Años del Rojas. (pp. 9). Buenos Aires: Libros del Rojas, UBA.

"Viturro, P. (2009). “Orgullo por partida doble”. En Calzón Flores, N. (comp.), 25 Años del Rojas. (pp. 227-228). Buenos Aires: Libros del Rojas, UBA.

»Wayar, M. (2007, noviembre). “Editorial (1)”. El Teje. Periódico travesti latinoamericano (1), p. 2.

»Wittig, M. (2006 [1992]). El pensamiento heterosexual y otros ensayos. Traducción Sáez, J. y Vidarte, P. Barcelona: EGALES. 